\title{
CONTENTS
}

Acknowledgments ix

Introduction: Inventing the Anthropocene 3

1 Nature, Wilderness, and the Environment: How Humanism and Efficiency Construct the Nature-Culture Divide 24

2 A New Materialist Environmental Rhetoric: Rhetorical Bodies in Relation 58

3 Affect and Intense Rhetorics: The Stickiness of Persuasive Entanglements 100

4 Persuasive Movement: The Rhetoricity of Things 132

Conclusion: From Anthropocene to Choracene: The Power of a New Materialist Environmental Rhetoric for Staying with the Trouble 167

Appendix 177

References 179

About the Author 193

Index 195 


\title{
Introduction
}

\section{INVENTING THE ANTHROPOCENE}

\begin{abstract}
I swat at black flies, horse flies—the sun scorching my already burnt neck and back. Even though I've already had five liters of water, I'm parched. I glance at my watch and groan. It's only noon. One more tree, one more tree, one more tree. One, two, tree! One, two, tree! The rhythm of tree planting resounding in my head. The silence of the clear-cut ringing in my ears; the only sounds are my breath, the thunk! of my shovel in the earth, the rustle of a tree in my bag as I pull it out . . . Three o'clock rolls around, and I've been replaying the same scene from Mrs. Doubtfire in my head for the past hour. Over, and over, and over, and over again. I'm going crazy, I think as I unwrap another 270 trees to put in my bags, and cram half a peanut butter and jam sandwich in my mouth. I've planted 3,000 trees at this point today, and there are still two? three? hours until quitting time. You plant until you're told to stop. As a tree planter, I am paid per tree that I plant-that is if it fits the specs that we are given: properly planted, no bent roots, not too shallow or deep in the ground, 1,400 stems per hectare, no leaning trees. There are a thousand ways to plant a tree wrong and only one way to plant it right, and you're only paid if it's planted right. Staring out into my land, I take a deep breath, and head out again. (Clement 2015)
\end{abstract}

Planting a tree symbolizes for most an uncomplicated positive endeavor, whether in the name of Arbor Day or as a backyard carbon offset in an age of unprecedented global warming. This book is about a different kind of tree planting, a kind that takes place on an industrial, unimaginable scale. A kind of tree planting that invents place intimately connected to rhythm, motion, intensity, and economy, as Stephanie Clement writes in the excerpt above from "To Plant a Million Trees." A kind of tree planting that happens by the thousands, on clear-cuts so large they can be seen from space. ${ }^{1}$ A kind of tree planting that requires human bodies, tree-bodies, and shovel bodies working in tandem to produce a seamless movement repeated hundreds of thousands of times in one planting season. This book asks you to understand industrial tree 
planting as something that tells the stories of both bodies and landscapes, as Anna Tsing (2015b) has it, stories that require considerations of human and nonhuman beings in the making of place. It asks you to understand industrial tree planting as a window through which we might view the constant invention and reinvention of the Anthropocene because without such windows, we have little way to grasp such an impossibly large human impact or even to attune ourselves to its scale.

This is a book about tree planting, but it is also a book about rhetoric, nature, culture, and environmental change and the ways they can be taken together to understand how it is that we are to live in ruin in the Anthropocene; and that it is not a static enterprise but rather a continual invention of particulars, situated in place and time. Such places of ruin are those that have been both simplified and abandoned in the quest to produce ever more material for consumption (6), as in the clear-cut as a space for replanted monocultured seedlings, a crop whose outcome and value in a human lifetime (it takes eighty years for the next harvest) are relatively unknown. It is a book about the ways human and nonhuman bodies make meaning of, dwell, and persuade each other to invent competing stories of the Anthropocene; to see humans as entangled with a range of nonhuman others; and to imagine what it means to be with each other in devastated landscapes. ${ }^{2}$

Our understanding of these landscapes is minor at best, since most of us live far away from the economic centers of the forestry industry—whose locations are, by design, remote-even if we do have everyday contact with its products, whether in the books we read or the toilet paper we use. By design, forest products seem completely disconnected from the trees they come from. Our national and provincial forests preserve relationships with trees that often separate cultural iconicity - the redwood forests of California, for example-from the facts of economic imperatives - 8 percent of the world economy is made up of the forest products industry (Ross 2015); nonetheless, we know we must strike a balance between consumption and sustainability. We cannot continue to consume without somehow planning for how we might consume again, which is what has brought about the contemporary tree-planting industry as a sub-unit of industrial forestry. Forests, as "natural" spaces, must now be managed by humans; and trees, as a renewable resource, may be cut down, planted again, and harvested again. As Shaul Cohen (1999, 428-29) notes, trees have both instrumental and emotional value, whether symbolically (as with the Tree of Life), metaphorically (representing a connection to the natural world), or futuristically (a measure of hope for generations to come in an era of global climate change). 
Some of the work to understand the "environmental panacea" brought about by planting trees in North America has been done by geographers and environmentalists who query its role in the nonprofit sector, examine the timber industry's public awareness campaigns, and investigate its successful message put forth by the US government; ${ }^{3}$ others have sought to examine forestry's often exploitive labor practices by undocumented Latino immigrants on US federal lands. ${ }^{4}$ Those who study tree planting as a social and cultural phenomenon have framed it in terms of gender, sexuality, and class; communities of practice; and nationhood and identity. ${ }^{5}$ It has thus far been seen through an examination of human social life. Unlike these prior studies, however, this book situates tree planting differently: as an activity that is not only part of how humans manage forests but also of how forests manage humans.

It is said that we are in the age of the Anthropocene, where humans are the primary geological force that shapes life on the planet. Of course, creating a geological epoch named after ourselves suggests the impossibility of imagining our way through it - after all, the end of the anthropos suggests the end of human life on earth. Yet if we imagine the Anthropocene as always-already, as never-ending, as statically here and not something that is invented, maintained, and in constant motion, it becomes nearly impossible to imagine futures that offer alternatives to self-annihilation. In suggesting that we turn our attention to the sites, words, things, processes, and sensoria that invent the Anthropocene, then, this book is part of the larger political project, as Donna Haraway (2015, 160) calls for, of making "the Anthropocene as short/thin as possible." Examining what it means to plant trees-to alter landscapes into plantations by constructing a particularized nature of a monocultured tree in a forest ecology_carries significant weight. Yet the stories we tell about this particular kind of living in ruin, stories that include what we might call "more-than-human sociality" (Tsing 2013, 27) through which we might consider the discursive, rhetorical, and material realms of silviculture, remain un-remarked in favor of the social, environmental, economic, and geographic realms. Thousands of popular press and scholarly articles documenting climate change, increased circulation of media calling for sustainable environmental management, and popular environmentalist messages that urge us to "leave no footprint" suggest that we prefer to think about silviculture in simple terms of carbon offsets and sequestration. Yet this book seeks to carve out a role for both the discursive and the non-discursive, the rhetorical and the material, among what exist as the new "illogical landscapes" proffered by those who plant trees for a living (Gill 2011,31). It is an attempt to provide, as 
Nathaniel Rivers $(2015,422)$ calls for, a more intense rhetoric located in both human and nonhuman forces. Such a project must situate rhetoric, then, as the footprint itself: "all the ways we mark and are ourselves marked, bitten, or stung." Living in ruin is a state of being. As Rivers (2015, 438) suggests, "Avoiding footprints is both impossible and ethically suspect."

As such, this book is a footprint. ${ }^{6}$ It is a mark on an Anthropocene that calls our attention to that which rests in liminal spaces-between human and nonhuman, intelligible and rational-as a move to examine place through the rhetorical act of placeholding. Such moves are acts of consequence because they ask us to understand the Anthropocene as made up of acts of constant invention, states of being and beingwith, rather than a foregone conclusion. The Anthropocene marks an epoch and also an argument. ${ }^{7}$ In other words, it is only possible to thin the Anthropocene when we are able to view it as one of many possible -cene-spaces - a shorthand that emerges through acts located in and over time, in constant action and motion, with varying levels of intensity, and with a constant need to catch up (since the now is already behind us). The casement for such a view, in Tsing's (2015b, 161) words, is the requirement that we "pay attention to the assessments through which we know disturbance . . . an open-ended range of unsettling phenomena" that "redesign the environment." Examining tree planting and its naturecultural entanglements is one such possible assessment. What better take on anthropocenic living? We raze forests to the ground. We plant millions of trees. Yet as Tsing reminds us, those acts are assemblages and in them are a million protagonists: pines, shovels, nation-states, muscles, resignation.

So what does it mean to plant a tree? In Canada, forested areas-that is, federally owned "public" Crown land available for logging and, later, planting-occupy 56 percent of the country, twice the amount in the United States and ten times more than Mexico. Between 12,000 and 15,000 Canadian reforestation workers plant trees on logged forests in any given year (Brown et al. 2004, 19), a markedly small number in an industry that represents the nation's largest source of export earnings. Yet in the national imagination, tree planting looms large as a rite of passage in Canada. Unlike the American silvicultural industry, which relies heavily on immigrant labor from Mexico (pineros), or the Mexican silvicultural industry, whose tree-planting ejidos and comunidades indígenas often live in extreme poverty (Brown et al. 2004, 19), Canadian tree planting - while seasonal contract work-is dominated by postsecondary students, a result of the stigma and refusal by local populations in the 
1960 s to do the work (Sweeney 2009, 77). As a result of a young, upwardly mobile, white, middle-class demographic engaging in the physically laborious work of planting trees, it is not hard to find stories of nostalgia, of connection to the homeland, of a "grueling but highly coveted job" (Luke 2014), and versions of an authentic experience of what it means to be Canadian. ${ }^{8}$ Unlike a parallel American demographic that has not heard of silvicultural work, since around 1990, unprecedented years of logging and increased reforestation employment have resulted in nearly every Canadian becoming connected to it in some way-a brother, a niece, a parent. It is a uniquely Canadian phenomenon in this way.

Thus to situate a study of tree-planter's discourse is also to draw upon Canada's historic struggle with defining itself as an independent, authentic nation: as Catriona Sandilands $(2000,169)$ suggests, the national project of "'Canada' is questioned by U.S. and global cultural, financial, human and natural resource flows." As a result, the nation depends specifically on narratives of geographic sovereignty to bind itself; one of the strongest is that of wilderness, a "situated narrative of desires for human and nonhuman relationships, one that may be underscored by a series of natural events and processes but is only given meaning and relevance in particular social and political contexts" (Sandilands 2000, 177). What it means to "be Canadian" is tied up in common relation to this shared landscape, a marker of national specificity and personal identity. Thus in turning to stories of planting this landscape, there is an inevitable turn to both culture-identity, belonging, territory-and nature, interactions with nonhuman actors and an idealized a-historical, a-cultural wildness. Yet it is precisely this impossible bifurcation of the nature-culture split, a Cartesian refraction of the subject and the object in a time of ecological crisis, that must be held up to scrutiny.

What this book seeks to do is reduce the friction between the subjectobject split by examining the rhetorical and the human in tandem with their interaction with other inanimate and nonhuman bodies, drawing on silvicultural work to make its case. Like other projects that seek to engage with inquiry into material sites, ${ }^{9}$ this project seeks to zero in on rhetoric as an a-theoretical attunement to being, an attention to rhetorical energy, in order to better understand the world. In keeping company with scholars interested in ontologies that seek to include humans within (rather than separate from) their environments, a dwelling, ambient rhetorical perspective-which characterizes the framing of this book-does not aim to contribute to a Cartesian logic that absents nature from culture and concepts from things; nor is it intended to conflate description of material objects with the objects themselves. Yet 
unlike projects that engage a material ecocriticism, my interests here are less critical and more rhetorical: I seek to examine what has been parsed generally by materialist ecocritics as "narrative agencies" (Iovino 2012) by putting forth a productive, rhetorical lens through which we might view and understand anthropogenic labor.

Rather than see rhetoric as a simplistic opportunity to somehow separate what is persuasive from the circumstances that surround any given material-discursive act, I promote an ambient rhetorical view (Rickert 2013), which, like other scholarship that lends credence to affect ${ }^{10}$ or to materiality, ${ }^{11}$ moves those who study language and material closer to navigating both from a dwelling perspective. Dwelling, for rhetorical scholars like Thomas Rickert (2013, xiii), suggests "how people come together ... in the continual making of a place; at the same time, that place is interwoven into the way they have come to be as they are." This notion of dwelling is no doubt influenced by the anthropological; Timothy Ingold $(2000,5)$ notes that the overarching endeavor of his book is to have readers adopt a dwelling perspective, in which they might accept that awareness and activity are rooted in the engagement between persons and environment for understanding perception and cognition, architecture and the built enyironment, local and global conceptions of environmental change, landscape and temporality, mapping and wayfinding, and the differentiation of the senses.

Ingold $(2000,5)$ insists that to adopt a dwelling perspective, we must acknowledge that "humans $\_$. are brought into existence as organismpersons within a world that is inhabited by beings of manifold kinds, both human and non-human." This call has been taken up in varied ways by rhetorical scholars interested in, for example, indigenous studies, object-oriented ontology and new materialism, as well as scholars in feminist science studies, the environmental humanities, and relational archaeology.

\section{THE LIMITS OF THE ANTHROPOS-: SITUATING NATURECULTURE}

The Canadian (and indeed, Western) notion of wilderness has specific connotations; that is, people know what they mean when they talk about it, and it has become a universalizing discourse. William Cronon $(1995,70,80)$ suggests that the discourse of wilderness itself, filled with memories, images, and sensations of interacting with things "irreducibly nonhuman"- that is, wild-reproduces that which it seeks to protect and "embodies a dualistic vision in which the human is entirely outside the natural." That is, a forest cannot be both wild and inhabited at the 
same time because wild spaces are natural spaces, and natural spaces are those where humans do not dwell.

Like other grounding modern Western dichotomies, culture/nature has kept good company with dualistic splits such as the mind and body or the subject and the object. The postmodern shift to deconstruct these dichotomies has provided deep framing for moving beyond these oppositional categories. However, as feminist scholars Stacy Alaimo and Susan Hekman (2008, 2-3) point out, postmodernism and its linguistic turn have served to make "the discursive pole . . . the exclusive source of the constitution of nature, society, and reality"-leaving material reality an entirely separate realm and thus "forclos[ing] attention to lived, material bodies and evolving corporeal practices." Turning again to a silvicultural "wild," if we accept the impossibility of separating landscapes from the bodies that change and are changed by them, we are forced to see the linguistic and material as part and parcel of living both in nature and against it-the tree, the talk, and the shovel as an assemblage of humans, nonhumans, and things. Planting the Anthropocene joins scholars in feminist science studies, indigenous epistemologies, ${ }^{12}$ and the environmental humanities ${ }^{13}$ who view nature and culture as mutually constitutive and who engage possibilities beyond dichotomous thinking-whether in providing the continuum of natureculture, acknowledging the role of the intuitive, spiritual, and moral (Berkes 1993, 4); engaging the discursive-material as an alternate framework; ${ }^{14}$ or taking on nature as agentic. As Alaimo and Hekman (2008, 5) suggest, engaging possibilities beyond these dichotomies also asks for new ways of understanding the world that turn from human-only instances of agency and consequence toward an accounting for "'intra-actions' (in Karen Barad's terms) between phenomena that are material, discursive, human, more-than-human, corporeal, and technological." To push ourselves away from the nature/culture dichotomy or to imagine nonhuman agency or to accept the fundamental role affect plays in connecting humans to nonhumans is to move toward a new kind of environmental rhetoric that does not imagine the anthropos as its only center.

The problem with contemporary environmental rhetoric, which leaves humans with only two options with which to consider the environment - to either be its savior or consume it as a commodity-is that "both [options] reduce environments to what we can say and do about them" while over-privileging human control (Rivers 2015, 427). The difficulty in ascribing a hubristic agency to human environmental action commits us to these same problematic bifurcations. In a tongue-in-cheek critique of humanistic environmentalism, Nathaniel 
Rivers $(2015,427)$ notes: "With the right amount of data and the correct political will, humans can reverse the trend of global climate change and save the earth. Through our awesome technological might we have rewritten the face of the Earth. Through our awesome scientific might we can now, finally, read the earth and see the true effect of our awful agency. But fear not, for it is that agency that will allow us to re-write (or right) the earth again." In his skepticism, we can read Rivers's frustration alongside that of Alaimo and Hekman's framing of a linguistic turn that has reestablished human beings from outside nature and situated the environment as "a code that can be read, mastered, and controlled" (Rivers 2015, 428). His call to engage Jane Bennett's (2010) vital materialism while considering issues of environment and environmental rhetoric similarly resonates with material ecocritics' call to consider nature as agentive, to examine the wildness and "thing-power" of objects. Swayed deeply by these arguments, my aim here is thus not simply to interrogate discourse and make grand claims about language and the construction of human reality in thinking through anthropocenic industry; instead, it is, as Bennett $(2010,116)$ urges, a "giving up" on "the futile attempt to disentangle the human from the nonhuman" in an effort to "engage more civilly, strategically, and subtly with the nonhumans in the assemblages" in which we participate. It is an attempt to recognize the invention of the Anthropocene while engaging with those who work through spaces of environmentalist-developmentalist polarities with their bodies.

I chose the title Planting the Anthropocene to recognize the tension inherent in the anthropo-, not a simple acceptance of its humandominated hubristic naming that recognizes and frames the existing idea that global environmental change has been and continues to be precipitated by human activities. Instead, its use is a signifier of boundaries and shifts. It stands, on the one hand, for arguments in Earth sciences that suggest its use represents a paradigmatic shift from thinking about Earth ecology, defined as "the science of the relationship between organisms and their local environments," to Earth System science, defined as "the science of the whole Earth as a complex system beyond the sum of its parts" (Hamilton 2015, 1). In thinking through the Anthropocene as metaphorical, the first ecological use, as Lauren Rickards $(2015,4)$ suggests, "equates the concept to 'global environmental change'; the second [systemic use] sees it as having exploded the modernist humannature binary that underpins global environmental change science." The Anthropocene is noticed here as a "boundary event", ${ }^{15}$ as a discourse ${ }^{16}$ as a slice of time that is one among many competing options: the Plantationocene, the Capitalocene, the Chthulucene. ${ }^{17}$ Through 
choosing the scope, process, and framework of this examination of natureculture by explicating narratives of silviculture, then, I recognize that to do so under the umbrella of "Anthropocene thinking" is to invoke throughout the "explosion" of the nature/culture bifurcation happening in both humanist and scientific fields.

\section{"SAVING THE PLANET" AND "PLANTING A CROP": PARTICIPANTS}

I first began this project because the subject matter was completely unknown to me but seemingly common for everyone I met. As a dual citizen, born in Canada but raised primarily in the United States, I had never come across tree planting as something salient in my own life. However, after returning to Canada and as a university professor, I found myself in situations that invoked planting and were made strange by my ignorance: at faculty brunches, someone would talk about how her nephew was planting trees over the summer and ten other folks would join the conversation, or I'd get into conversations with students who described their summer plans for seasonal work. In other words, it seemed as though I had stepped into something no one else seemed to think was anything special. I had no grounding to the Canadian landscape as a particular kind of industrial resource; the closest I had come to understanding this particular topoi was in terms of the contract work and management of the Alberta oil sands. Curiosity and these problematic parallels drew me to silviculture.

Because tree planting is so common and networks of planters are so close, participants were easily recruited for the project. Although I gleaned through interviewing them that some of the planters who participated knew each other, none knew beforehand to whom I had spoken. Thus I began the project by interviewing a former student, who sent me names of and contact information for people who were interested in the project; I visited a forest wildlife management class and handed out my contact information; I sent an email to a local environmental listserv explaining the project. I did not place barriers on age, time spent planting, or gender. From these gestures, sixteen interviews took place with a variety of participants, yet most were white, young, and middle class. Five were women and eleven were men, though since the 1990s the female workforce in tree planting has risen in number to be nearly equal that of men (Sweeney 2009, 69) and interviewees were not meant to represent the particularities of silvicultural demographics. What all participants had in common, despite experience planting often in Canada's western provinces that dominate the industry (British 
Columbia and Alberta), was their connection to the prairie province of Manitoba, where the interviews were conducted. This is significant in thinking through geographies of planting, as Manitoba (as part of the west/central region of Canada) has fewer reforestation companies and plants fewer trees than most provinces to the west and even the eastern province of Ontario.

Generally speaking, there are fewer forested areas, less planting, and less data about the experiences of planters as one moves east. ${ }^{18}$ The little research that exists on Canadian planting focuses on a specific region, usually British Columbia ${ }^{19}$ or Ontario. ${ }^{20}$ Thus participants' experience reflects a relative diversity of planting not relegated to a particular region, with slight additional information about planting in the East, something with which only a few planters had experience.

When I began interviewing planters, I was operating from the position that I was recording histories of their experience that others might use in the future; since this was an oral history project, all participants agreed to be identified by name. ${ }^{21}$ Currently, data available about tree planters specifically (as opposed to forestry workers such as loggers, forest contractors, foremen, logging road construction workers, and mechanical repairpersons) are limited. ${ }^{22}$ The voices I add to the existing literature on tree planters in Planting the Anthropocene take up the complicated position forestry workers hold about their relationship to the environment, documented notably by Thomas Dunk's (1994) work with loggers (or "cutters"). Dunk (1994, 17) suggests that both ambiguity and contradiction characterize forestry workers' relationship with the environment and their response to environmentalism; as he notes, these complexities in perspectives of those who work in the forest "highlight the need to break with economic-determinist ways of thinking about environmental debates." Although loggers depend on the forest for wages and report having "no use for" environmentalists (Dunk 1994, 24), they also report concern over widespread herbicide use, clear-cutting, tree waste, soil erosion, mechanical harvesting, and singlespecies planting (Dunk 1994, 21). Throughout the interviews, Dunk $(1994,23)$ notes that "many workers attempted to define the boundary between the natural and the unnatural (what anthropologists might think of as the distinction between nature and culture) and situate their own activities in relationship to this boundary." As he suggests, "We live both in and against nature but few of us have to live this contradiction in our everyday lives" (Dunk 1994, 22).

While Dunk's $(1994,23,17)$ scholarship ultimately falls into the same privileging of the culture/nature divide (suggesting that "in the end it is 
culture that determines how one defines the boundary between nature and culture"), listening to the confusion and ambiguity produced by those who work in forests represented in his study suggests that there are more complicated positions inherent in rhetoric surrounding a "job-versus-environment narrative." It is not enough to assume, then, that humans who cut down trees for resource extraction do not see themselves as having environmental values; similarly, what became evident in talking with tree planters (who represent the last, rather than the first, stage of industrial forestry) is that it is not enough to assume that humans who plant trees in the name of resource management necessarily think of themselves as saviors of the forest. ${ }^{23}$ As Thayer, one of the planters I interviewed, said, "Particularly earlier on in the season, I spent a lot of time thinking about myself planting a forest, and by the end of the year actually my perspective was altogether different. I was planting a crop, and it took me a while to reassess that" (T. MacInnis, unpublished data). This realization is echoed by nearly all the planters who participated in this project and represents, $I$ argue, a call for a dwelling perspective that does not make the way forward for environmentalism as a simple separation between human impact and conservation, between culture and nature. Instead, it suggests that we can live both in and against nature, that we can grant "nature" (that is, nonhuman assemblages and materials) agentic force to change minds and resist human control or codification. It suggests, as I note in chapter 3, that human and nonhuman entanglements allow a more nuanced affectual engagement with environmental destruction and loss that does not fall simply between these two positions, an engagement that represents an opportunity for reckoning and reinvention. We might embrace the idea that, as Rivers $(2015,428)$ argues, "the environment is finally not a problem to be identified and then solved, but a fundamental agonism (a krisis) that we must always work through." Such a recognition is the basis for what I am calling here a new materialist environmental rhetoric, which brings together the work of material ecocriticism and critical affect studies as a frame with which to work through environmental krises.

\section{METHOD-METHODOLOGY: NETWORKED PRACTICES}

Undertaking this project has meant accepting Donna Haraway's (2008, 159) argument that nature is both topos, a commonplace with which to order discourse, and tropos - a turn, or movement toward and away. This book does not attempt to pin down or construct an image of the Canadian "wild" or anthropocenic "ruin." Yet it does frame the attempt 
to order human and nonhuman actors in silvicultural narratives as a way of giving place to them and recognizes, in so doing, that "how to give place to something is an issue of invention" (Rickert 2013, 63).

To that end, my thinking through Canadian narratives of silviculture has been informed methodologically by theories of ambient rhetoric, which, like other theoretical perspectives from feminist science studies, political theory, posthumanism, ecological postmodernism, and new materialism, seek "ontological hybridity" (Gries 2015, 5). As a researcher of rhetoric, I am invested not only in what words mean but also in how they attune users to being in the world. Planting the Anthropocene is an effort of chorography that recognizes that "minds are at once embodied, and hence grounded in emotion and sensation, and dispersed into the environment itself, and hence no longer autonomous actants but composites of intellect, body, information, and scaffoldings of material artifacts" (Rickert 2013, 43). While some of the finer elements of chorography go undefined in Gregory Ulmer's (1994) original rhetorical use of the term, they've been taken up by scholars who have used this framing to situate the act of inventing place using associational and analogic thinking. ${ }^{24}$ Thus this project, like others that invoke the chōra as a place where things begin and also as an organizing inventional principle, a "cultural space that emerges between metaphysical and physical space" (Hawk 2003, 75), also understands chōra as a continually invented place, attuned to the material and the affective. ${ }^{25}$

In positioning myself as a choric rhetorician, then, I recognize that Planting the Anthropocene has been shaped throughout with an intention to "attend to memory, networks, technologies, intuitions, and environments (places), because these things all touch on place as something generated, not statically present and hence prereceived" (Rickert 2013, $67)$. Much of the organizing principle of the book, then, relies on the choral word: an attunement to roots, dreams, flies, machines, thinking less "linear indexical" than "network associational" (Ulmer 1994, 36). What this has meant for the methodological framing of this book has been a different kind of listening to participants, an allowing for objects and nonhumans patterned through discourse to speak and arrange chapter content, allowing intuitions to count as data, to imagine material and affect as having both an organizing and a persuasive function, and to imagine the associations among these assemblages ${ }^{26}$ to construct a character of a cut block, of an anthropocenic landscape, of a new Canadian geography.

Methodological support for choral thinking has emerged from a range of interdisciplinary work, much of which comes from both critical 
affect studies and feminist new materialism and from scholars who have worked to generously engage the work of Baruch Spinoza, Martin Heidegger, and Gilles Deleuze and Félix Guattari or to carry it forward (i.e., Bruno Latour and Graham Harman). While I primarily rely on the work of rhetorical scholars who have engaged this scholarship, writing this book has taken detours into philosophical thinking about the place of humans, animals, plants, and things that would be impossible without these thinkers and writers and those who have taken them up in a range of disciplines, whether in politics (Jane Bennett), anthropology (Anna Tsing, Annemarie Mol), plant neurobiology (Anthony Trewavas, Michael Marder), feminist science studies, affect studies, and new materialism (Karen Barad, Donna Haraway, Diana Coole, Samantha Frost, Sara Ahmed, Teresa Brennan, and Rosi Braidotti) or material ecocriticism (Serenella Iovino, Serpil Opperman). While I have read widely in a range of areas to help lay this groundwork, the scholars I've gathered here together similarly refuse to allow the codification of the natureculture binary to unproblematically stand.

This interrelation of mind and matter, the interruption of logic as detour to reason, the acknowledgment of bodies as sets of relations, and a firm rootedness in Diane Davis's (2014) claim for an "underivable rhetoricity of being" constitute the methodological infrastructure that undergirds choices about research methods. Here my approach to interview data sees those data not only as a qualitative research method or a collection of oral and aural-historical accounts but also as collective acts of description by participants. In so doing, I wish to reclaim description as a central method for understanding complex systems. In the spirit of the scholarship of Sharon Marcus, Heather Love, and Stephen Best $(2016,11)$, whose work counters the contemporary intellectual view of description as filled with risk and even contempt, I view the descriptions provided by interviewees as complex attentions to messy details. Obviously, interviews with humans are not interviews with trees or crows or trucks, even as, perhaps, the humans from which these interviews spring are themselves multi-species assemblages of bacteria, microbes, and parasites and thus are always "speaking with." What these interviews are instead are outbreaks of assemblage thinking that allow us, as Bennett $(2010,108)$ suggests, an opportunity to "listen and respond more carefully" to the nonhuman elements within them. Humans only ever understand meaning making through the limits of the anthropos, even as other living and non-living bodies make meaning in other ways, whether through assemblage, bodily form, reaction, or transformation. 
Yet humanness is also, as Tsing $(2013,34)$ reminds us, "a place to begin." Interviews with tree planters and the questions and intersections they invite with nonhuman others allow this book to delve into what Tsing (2013) calls critical description. ${ }^{27}$ As an act of critical description, this book both asks urgent questions and demands a curiosity about bodies, affects, and things that implicate the material within the linguistic, see humanness as a way in, and networks such a method with the methodological interventions of those working in the disciplinary fields I've mentioned. In viewing interviews as a method that invites and sometimes bridges critical description, I am also urging readers to see such descriptions for their invocation of nonhuman worlds, to know that we "learn them and ourselves in action, through common activities"-a move, Tsing $(2013,34)$ suggests, "from technological and ethical object making to pursuing the social worlds of these objects in motion." She reminds us that projects like these "might begin with arrangements humans set into motion, but then [they] trust guides such as form and assemblage to tell us about social relations in which we are only indirect participants" (Tsing 2013, 34). Thus Stephanie Clement's opening invocation of the one, two, tree! motion of planters on the landscape, her encounters with black flies and horseflies, sun and thirst, tree seedlings and shovels, are all ways in - for the rest of us-to understand persuasive assemblages woven from human and nonhuman relations on the silvicultural landscape.

The descriptions provided by tree-planting interviews are a way in to the testimonies of the living and nonliving bodies they take up, the chōra they construct, and the forms and assemblages they ask us to consider. They are a beginning way-insomuch as any text-based project is not also a walk in the woods-for readers to engage in complex silvicultural worlds of humans, animals, plants, and things they are distanced from in the same way reading such descriptions captures our own distanced experience of connecting the page in our hands to the same pulp-paper-silviculture process tree planters are describing. We are, all of us, complicit in inventing this anthropocenic moment. Such a view emboldens description as a method that allows us to engage with the vitalness of material because stories contain affectual richness that is "responsive to the liveliness of material relationships" (Marcus, Love, and Best 2016, 8). ${ }^{28}$ Such richness, in its most promising form, works to further unseat the subject/object divide and, it is hoped, draws us toward our own recognition of environmental loss and complex movement forward. It also suggests that these descriptions are simply a thickly dripping part of the chōra-words that planters speak are part of the 
assemblage of bodies and worlds that move, reflections of relationships and liveliness among humans and things. Thus, it is my intention for readers to acknowledge the (often lengthy) descriptions provided by tree planters "as a collective, networked social practice"-which here includes nonhuman sociality—or as Marcus, Love, and Best (2016, 9) suggest, as "neither the view from nowhere, nor simply the view from somewhere, but many views from many places, over time." In engaging interview data as views from many places over time-inviting human description as ways in to nonhuman forms and assemblages-such multiplicity also acknowledges the attendant uncertainties and messes that accompany figuring sensory worlds through words.

\section{DWELLING PLACES}

The silvicultural workers and their experience as represented by interview data are often ambiguous, sometimes contradictory. It has been a messy practice to try to make sense of their words and worlds, wanting to construct a Canadian topos-some fixed insight about the land, about the people-but only being able to locate chora, indeterminate and associational. In gathering together the details of the interviews-the human and nonhuman mentions, the invocation of the body and its movement, the realm of the affective - my purposes have been twofold. First, I have been looking to move through environmental rhetoric as an ongoing krisis by offering a rhetorical lens that provides insight into the ways theory and method interoperate, suggesting that rhetorical scholars and researchers might situate chorography (and ambient rhetorical approaches) as something not only relegated to the realm of unbounded, aleatory generativity but also as a grounding methodology for an extended research case. While some degree of this work has been accomplished, notably by scholars like Byron Hawk (2007) (in examining the film The Fifth Element), Jeff Rice (2007) (in examining the rhetoric of cool), and Thomas Rickert (2013) (in using examples of Toronto Island and the EV1 electric car), this book diverges somewhat from prior choragraphical scholarship. Unlike the tradition of chorography used primarily in the realm of the digital-to "update the topoi" (Rice 2007, 33) -instead I use it here as a framework for the rhetorical-material. Second, this book seeks to use chorography as the principle that binds and gives meaning to a phenomenon-tree planting-through an extended examination of its discursive presentations. Planting the Anthropocene deviates from the usual choragraphic approaches, then, in inventing the cultural space of silviculture rather than examining 
its appearance, for example, onscreen and online (as, for example, in the documentary 78 Days). To that end, Planting the Anthropocene is an attempt to write silviculture "through its connections and meanings" (Rice 2007, 40) rather than as a definitive textual source or through new media, to travel the lines wrought out of tree dreaming and tendonitis to attempt to capture a particular perspective on dwelling in the Anthropocene. Scholars have named the gathering of these perspectives in different ways. Debra Hawhee (2017) argues for a "rhetoric of tooth and claw," Haraway (2016a) asks that we "make kin," and Haraway and Tsing (2015) argue for a storying of resurgence, the changing of an ecosystem by plants and animals that emerge after a quick, large-scale ecological disturbance (such as fire, flood, or farming). If, as Tsing (2015b) has argued, the Anthropocene is marked by the complete denigration of refuge, then examining the moment in which "cheap nature is over" for the precise outcome of thinning and shortening the Anthropocene is long overdue (Haraway 2015, 160).

As an extension of these observations, Planting the Anthropocene suggests that tree-planting discourses, as markers of dwelling and one human way to story resurgence, are representative of persuasive relations in human-disturbed forests that offer the possibility to rethink human relations to nature. One way to rethink our relations, I argue, is by engaging a new materialist environmental rhetoric. Such a rhetoric accepts the relational materiality offered by material ecocriticism and theories of affect as put forth by scholars of critical affect studies (CAS); however, in its emphasis on the rhetoricity of bodies- that is, the persuasive effects a multitude of bodies generates-such an approach can be distinguished from others that may differentially emphasize biosemiotics, ecopoetics, ecological postmodernism, or transcorporeality. Such a lens is one through which we might view the messiness of tree-planting descriptions: planters embrace in their narratives both the problematics of rhetorical humanism (which posits individual choices against an objective world) and efficiency (equating time with money and thingcapital) while at the same time countering them with alternative persuasive practices of body, things, machines, and affect that break down the separation of individual from material environment.

To understand the tensions between anthropogenic work and tree planting geographies, in chapter 1 I provide a historical overview of common discourses of nature, wilderness, and environment that have ruled human ways of thinking about the relationship between nature and culture to show how deeply rooted they are in the split of subject from object, self from other, and nature from culture. This 
divide is what constructs the availability of the common rhetorics of humanism and efficiency tree planters so often draw on to frame their narratives-rhetorics that, as Rickert (2013) notes, work as moves that further separate humans from the material world. Drawing on the work of David Harvey (1996) and William Cronon (1995) in complicating the idea of nature, environments, and landscapes and their relationship to human modification, disturbance, and thing-capital, chapter 1 focuses on the ways tree planters' discourse describes struggles with the dualism between culture and nature and between environmentalism and developmentalism. This is represented by the common invocation among interview participants of a particularized individualism, an idiomatic assessment of land value, and a consideration of trees as capital. It also explores the rhetorics of efficiency that run throughout the interviews, in which planters overwhelmingly equate time with money. Chapter 1 positions the expected and found problematic narratives of work, technological progress, humanism, and efficiency (which separate people and environments) against later naturecultural alternatives of dwelling (which enmesh people in lifeworlds), represented by taking up a new materialist environmental-rhetorical approach in chapters 2-4.

In chapter 2, I turn to the work of Diane Davis (2014), John Mucklebauer (2011, 2017), Debra Hawhee (2017), Brett Buchanan (2008), and Jeffrey Nealon (2016) to situate patterned planting references in the interview corpus that dwell on human-nonhuman interaction. In so doing, I put forward three major premises that guide the rest of the book: (1) that we need not depend only on logos to define a rhetorical way of being in the world, (2) that there is an "underivable rhetoricity" (Davis 2014, 536) that unites human and nonhuman bodies, and (3) that we understand bodies as sets of relations. Together, these ideas frame a new materialist environmental rhetoric by examining the role human and nonhuman interaction plays in tree-planting narratives, and they give rise to the book's main argument: reflective of human-nonhuman entanglement, such descriptions also complicate narratives of humanism and efficiency and challenge the nature-culture bifurcation. In turning to planters' unanimous descriptions of pain and pleasure, animal encounters that shape decision-making, and the rhetorical force of plant bodies, I argue that the realities of dwelling with nonhuman bodies both challenge the logos of efficiency and self-determination and reflect possibilities for environmental rhetorics that are attuned to messy and complex notions of timescale and bodythinking.

Building on these arguments, in chapter 3 I turn specifically to affect as a way to anchor an ambient perspective. Here I draw on 
rhetorical-ecological thinking put forth by Jenny Edbauer Rice (2005, 2008), as well as that of scholars invested in rhetoric's sensorium (Hawhee 2017) and critical affect studies (Ahmed 2004, 2010; Brennan 2004), to focus primarily on the non-rational as a source of dwelling. With the aim of embracing the "messiness" of affect rather than continuing to propagate theories of emotion that divvy it up between mind and sensation, chapter 3 locates itself within Sara Ahmed's $(2004,1)$ assertion that "emotions shape the 'surfaces' of . . . bodies" while acknowledging the range of bodies present in planting work, as situated in chapter 2. Planters categorize their experience of planting along affective axes: as an experience of bodily intensity, in the meditation and mindfulness or "infinite resignation" generated by repetitive movement, as a site of encounter with nonhuman bodies: trees, animals, shovels, weather, and water. In viewing affect as produced out of multi-species encounters and "contact with objects" (Ahmed 2004, 7), chapter 3 suggests that these complex entanglements allow us to recognize tree planting as an event that is not mired in the media creation of a pristine nature-fantasy but instead allows a naturecultural middle ground, a reflection on dwelling, and an intense environmental rhetoric (Rivers 2015, 422).

I extend this notion of intense rhetorics in chapter 4 by turning specifically to thing-bodies as they co-invent the planting landscape. Drawing primarily from the work of Jane Bennett (2010, 2012), who argues for the vibrant materiality of things, and from the work of rhetorical scholars in the area of rhetorical ontology (Barnett and Boyle 2017; Pflugfelder 2017), in chapter 4 I turn to the ways human entanglements with things-trucks, roads, and helicopters-draw attention to the ways persuasive movement co-constitutes the planting landscape and interrupts common assumptions about the nature-culture divide. Focusing on the ways everyday thinking about automobility, infrastructure, time, and speed is enabled and constrained by thing-bodies on the landscape, I examine the ways thing-bodies work to enable and constrain particular discourses about human efficacy and control. Examining the mythos of personal freedom, economic prosperity, and political integration suggested by the promises of infrastructure and automobility, in chapter 4 I move outward from the planter body and its circulating affects of efficiency and humanism to examine some of the ways these affects circulate in the world. In looking at some of the animating materiality of rhetoric, such as the way a road might enable an Indigenous fight against the fossil-fuel industry or the way a helicopter might promote efficiency discourses, I argue that these kinesthetic rhetorics (Pflugfelder 2017, 
17) orient us in ways that no longer have the luxury of differentiating nature from culture.

In the fifth chapter I conclude that living in ruin in the Anthropocene exhorts us to account for the ways disturbance-based ecologies reveal themselves as subtle, nuanced, and in flux. In doing so, I offer the new materialist environmental rhetorical framework I have been articulating as one possible way we may learn to "stay with the trouble" (Haraway 2016a) of the Anthropocene so we can resist its discursive power, which presupposes impossible foundations for future living and being. In reflecting on this account of tree-planting work, I draw on the ideas of Haraway and Tsing, who entreat scholars to find ways of reconfiguring relations between the human and nonhuman to move beyond the Anthropocene. In putting forth a framework for a new materialist environmental rhetoric that acknowledges new networks of things, places, and being, I locate possibilities for chorography to disrupt the continuity of an Anthropocene that allows us only to envision outcomes that leave us filled with either hope or despair. I close by identifying other sites of anthropogenic work that would benefit from analysis that bridges the gap between ecocentrism-valuing nature for its own sake-and anthropocentrism: valuing nature because of material or physical benefits it can provide for humans.

Although I cannot claim for this book an approach to natureculture that has engaged with what is increasingly known as Indigenous research methods in its design (Chilisa 2012; Wilson 2008), I would be remiss if I did not acknowledge the ways the perspective and rhetoric I espouse here have long been at play among those whose voices we listen to the least. To that end, I recognize that many of the ideas from feminist science studies, the environmental humanities, affect studies, and new materialism owe a great debt to a worldview that encompasses all our relations ${ }^{29}$ and comes from Indigenous people around the world. I hope that what I offer here will be seen as an effort at reconciling these relational ontologies to better attune us to sites of resurgence-accounts where we might better observe nonhuman arrangements and desires within them and better assert the impossible bifurcation of nature and culture. In granting readers a view of the Anthropocene through the dwelling space of tree planting, it is my hope to enable a reimagining and reconfiguration of the ways one might work and write through encounters and entanglements with nonhuman others. Although work in plant ecophysiology, botany, and forest ecology increasingly show us the ways forests themselves are resurgent creative and connected lifeworlds, I echo Haraway and Tsing's (2015) argument that these stories—stories 
of ruin, of disturbance, of "feral biologies"—need to be told, not just by scientists but also by humanists. In examining the ways the phenomenon of silviculture is given meaning across a range of bodies, things, affects, machines, and places, I align these knowledge-making practices with John Law's (2004, 3) assertions about method: that we must "find ways of knowing the indistinct and the slippery without trying to grasp and hold them tight." Shortening and thinning the Anthropocene, putting forth natureculture as the obvious and unavoidable epistemological choice in moving us forward, means living as rhetorical beings in flux and engaging in listening processes that are themselves as messy, recursive, and reflective.

\section{NOTES}

1. See Natural Resources Canada (2002) for a discussion of remote-sensing (satellite) methods of mapping clear-cuts.

2. I take the term devastated landscapes from Catriona Mortimer-Sandilands (2010, 334), who suggests that spaces of ruin such as cut blocks or nuclear power plants are affective spaces of melancholic loss that foreground an acknowledgment of complex human-environmental relationships.

3. See Cohen 2004.

4. See Sarathy 2012.

5. For representative discussions of these approaches, see Ekers 2012; Sweeney and Holmes 2008; Ekers and Farnan 2010.

6. Rivers $(2018,186)$ suggests that the footprint trope might be better understood as a means of wayfinding rather than only transport. It is in that spirit that I suggest the metaphor.

7. The Anthropocene is noted by the layperson as often metaphorical, an age in which humans are causing large-scale environmental and planetary change. For scientists studying geological time through examination of Earth layers, the Anthropocene has yet to be registered. For a discussion of the distinctions between Anthropocenic and Holocenic time through an examination of stratigraphic records, see Waters et al. 2016. For a nuanced examination of an interdisciplinary argument of the Anthropocene beyond a geological time perspective, see Haraway et al. 2016.

8. See Plummer 2012; "Vintage" 2014; "Let's Talk" 2016 for further examples.

9. See, for example, Mazzolini's (2015) work with Mount Everest or Tsing's (2015b) work with matsutake mushrooms.

10. See, for example, Edbauer 2005; Micciche 2007; Gross 2006.

11. See Selzer and Crowley 1999; Gries 2015; Barnett and Boyle 2017.

12. For a discussion of the differences between Western ecological knowledge and what is known as "Traditional Ecological Knowledge," which draws from an amalgamation of Indigenous knowledge of ecology, see Berkes 1993.

13. For a discussion of current thinking on the environmental humanities, see Neimanis, Åsberg, and Hedrén 2015.

14. See Strathern 1980; Haraway 2008.

15. See Haraway and Tsing 2015.

16. See Crist 2013.

17. See Haraway 2015. 
18. Eastern Canada is made up of Quebec and the Maritime provinces of NewfoundlandLabrador, New Brunswick, Prince Edward Island, and Nova Scotia; see "About the Regions" 2013.

19. Ekers 2012; Ekers and Sweeney 2010; Roberts 2002.

20. Sweeney and Holmes 2008; Sweeney 2009.

21. Ethics approval was obtained through the University of Winnipeg Human Research Ethics Board, \#HE02559. See a list of interview questions in the appendix.

22. Everything we currently know about tree-planting work is represented by 46 planters in Sweeney and Holmes's (2008) study of tree planting in Ontario, 35 interviews with British Columbia planters in Ekers's (2012) work, 13 planters in Bodner's (1998) unpublished thesis, 6 pineros in the Jefferson Center for Educational Research's (2003) "Voices from the Woods" project, and 28 American forest workers in Sarathy's (2012) book-length work on pineros (although the exact number of planters is unspecified). Thus, what we currently know about tree planting, despite its cultural capital in Canada, can be summed up in ethnographic and interviewbased studies of 100 people, slightly more if one considers data collected in the United States about pineros.

23. See Sandilands 2002 for a broader discussion of the privileging of consumptive constructions of nature over productive ones.

24. Morrison (2001, n.p.) clearly articulates that chorography is "(1) 'learning how to write an intuition [ . . ] or is reasoning as intuition' (37). The chorographer is an 'active receiver' and writes with 'paradigms (sets), not arguments.' It's also (2) the 'generative potential of specific geography' and encountering 'unexpected and different factors and associations' affecting the character of a place-or a 'field,' 'premises' (in its various senses, including real estate and the logical grounds of reason or the propositions from which a conclusion is induced) (40). Chora (3) has to be approached 'indirectly, by extended analogies,' so [it] is inherently ambiguous; it's neither in the order of the sensible nor of the intelligible 'but in the order of making, of generating' (67). To locate the 'choral word,' (4) one must be attuned to coincidence" (n.p.)

25. See Hawk 2007; Holmevik 2012; Liestol, Morrison, and Rasmussen 2004; Gries 2015; Rice 2007.

26. I recognize here the groundbreaking work of Deleuze and Guattari (2003 [1987]) in coining "assemblage" as a conceptual framework for thinking through matter and material. For a larger discussion of its use and meaning, see Marcus and Saka 2006.

27. Tsing $(2013,28)$ defines critical description as follows: "critical, because it asks urgent questions; and description, because it extends and disciplines curiosity about life."

28. Marcus, Love, and Best (2016, 9-13) note that building better descriptions makes space for allowing knowledge to overlap with its knowledge object (rather than maintain critical stances of tautology), for embracing the uncertainty that characterizes trying to understand the sensory world through words, for engaging stray details that create possibilities from the strange, for "attending to the describers as much as to the described," for allowing the instability and changeability of description that encourages "responsive wandering," and for questioning objectivity as both "impossible and undesirable."

29. "All our relations," from the Lakota phrase Mitákuye Oyás'in, is often used widely in Indigenous prayer, reflecting on the oneness of people with their surroundings. Both Powell (2011) and Chilisa (2012) mark such a premise as a starting point for research. 


\title{
NATURE, WILDERNESS, AND THE ENVIRONMENT How Humanism and Efficiency Construct the Nature-Culture Divide
}

\begin{abstract}
The first feeling, I guess, out there was when Eric left me on my piece of land and said "plant" and walked away. I just remember looking around. I had a big swampy piece, and [I was] not seeing a single god damn bräcke. ${ }^{1}$ And I'm thinking to myself, "where the fuck am I supposed to put the tree." And as soon as I thought that I was standing around and I thought: "oh my god you're supposed to be planting like fifty of these in a minute." And I started panicking, "I can't just stand here. Oh god, oh god!" and like looking around for anyone to help me. Finally Eric came along and he made the hole for me for the first little-whatever. But you know I mean the first two weeks weren't that bad (Kailen, June 12). (Bodner 1998, 85-86)
\end{abstract}

The worlding of our contact with "nature" is filled with terminology that helps us separate ourselves from it with greater clarity. We often don't recognize the ways discourses of nature are pitted against culture or the ways such discourses depend on humanism or have been managed with efficiency in mind or even, perhaps, the ways those discourses constrain the stories we can tell. In this chapter I unpack some of the ways nature terminology—nature, wilderness, environment-contributes to a specific geography of tree planting. This geography not only depends on a particular understanding of spatial discourse and material relations but also helps explain the ways tree-planter bodies (as separate from a simple human body by virtue of their constant contact with both shovel and tree) are already attuned to particular arguments about these landscapes, as Kailen's excerpt above suggests. It is in the spirit of seeking to understand those specific geographies-and the way they invent particular anthropocenic moments-that I draw on contemporary definitions of these terms thoughtfully constructed by geographers, environmental humanists, anthropologists, and environmental 
historians who have sought to problematize nature-culture divides in their explanatory work.

What contemporary theorists of space and place have in common is recognizing a long Western tradition of accepting as true that humans are separate from their environments, commonly positioning "nature-as-other" (Sandilands 2000, 179). This separation is ubiquitous in everyday life: common invocations of distinctions between native and introduced/invasive plant species, the frequently urban-planted sugar maple tree and the old-growth sugar maple, the farm and the forest. It also contributes to common philosophical divides between environmentalists and ecologists, as David Harvey $(1996,118)$ points out, allowing environmentalists to "adopt an external and often managerial stance towards the environment" and ecologists to "view human activities as embedded in nature . . constru[ing] the notions of human health in emotive, esthetic as well as instrumental terms." Increasingly, scholars are turning from this common divide, pointing to the historical ways these distinctions have emerged and the damage they have done by continuing the subject-object split between humans and the environments in which they live. ${ }^{2}$

The common separation of humans from environments sets up a naturalized discourse about the physical world that takes as foundational this disconnection of culture from nature. I use the term discourse here in its Foucauldian sense, that is, to describe "practices that systematically form the objects of which they speak" (Foucault 1969, 49), thus both enabling and constraining what is possible to say in any given moment and constructing specific realities about any given object-in this case, the natural world and human relations within it. The ways humans have circulated knowledge about their relationship with the natural world in the last 500 years have everything to do with the ways humans can or can't talk about these relationships today. Foucault $(1969,49)$ suggests that "one cannot speak of anything at any time; it is not easy to say something new." As such, the ways Western notions of nature, of wilderness, and of environment are constructed over time set up a fairly rigid script for thinking about the world in which we dwell, as I take up next. This nature-culture divide sets up a discourse and a rhetoric about nature that is nearly impossible to escape, particularly for forest workers. Thus a brief discussion of common nature terminology is useful for framing an understanding of how tree planters arrive at the particular discursive geography of planting that they do, which takes for granted humanism and efficiency as normalized. I take up these brief histories of nature, wilderness, and environment to recognize that these terms not only set up 
common patterns of description that invoke rhetorical humanism and efficiency but also construct patterns for us that are nearly impossible to avoid, given the anthropocenic commitment to situating humans separately from lifeworlds over a great deal of human history. As I turn in later chapters to arguing for the larger theoretical framework of a new materialist environmental rhetoric, it's important to note the discursive boundaries and constraints such a history embodies, since no human exists completely outside of them. In examining planters' discourse, I show how these patterns get articulated in the everyday experiences of replanting labor. Yet in revealing the inconsistencies of the logics of humanism and efficiency that also appear, I argue that there exists some possibility to imagine dwelling alternatives to these limiting rhetorics, which can invoke ambient ways of being in the world that are corporeal, affective, and material.

\section{THE WRONG NATURE}

The nature-culture divide is attributed to the movement of rationalist thinking in the late seventeenth century, spurred by the scientific revolution and the work of Enlightenment thinkers. As Neil Evernden (1985) points out, Galilean thought, upon which much of the scientific revolution was founded, suggested that science depended on assessing the world as "if living creatures were removed" (Galilei 1957, 274). Galileo was the first to suggest a distinction "between what was measurable and therefore 'objectively' ascertainable-being the same for everyone-and what was not measurable and therefore varied from person (subject) to person (subject) — that is, was subjective" (Pepper 1996, 138). Galileo imagined a measurable world without humans, giving credence to the "inherent qualities of objects" (139), thus separating primary object-qualities (objects' qualities such as size, shape, number, motion) from secondary object-qualities (subjective qualities known only through human interference, such as color, taste, smell, sound, and perception of temperature).

This distinction between object qualities as those that exist "out there" and those that are "in here" was the foundation of Cartesian and Baconian thinking, which similarly bifurcated the mind from matter, just as Galileo had separated subject from object. This bifurcation is the fundamental ground on which the nature-culture split rests. As David Pepper $(1996,141)$ argues: "Nature became composed of objects metaphysically separated from humans. These objects had primary qualities and no others. They were reducible to atoms, whose unthinking, 
machine-like behavior was universally the same and explicable in terms of mathematical laws. Humans, by contrast, were defined as rational thinking beings—-subjects who observed objects, including nature, and could impart secondary qualities to them." Here, the separation of self (human) from Other (nature) is the most basic distinction, played out as the acceptance of rational human/culture (subject) separated from mechanistic nature (object). Such a view, as Evernden $(1985,18)$ contends, has resulted in "people accepting as normal a view of nature from which they are excluded."

Although the impossibility of this "normal" view has been noted in contemporary studies of anthropology, geography, sociology, and ecology, ${ }^{3}$ the common anthropocenic view of nature existing outside the realm of the human persists, as is evidenced by the major perspectives on nature put forth by rhetorical scholars M. Jimmie Killingsworth and Jacqueline Palmer (2012). In their useful model, they frame public rhetorics of environmentalism (mainstream science, news media, environmental impact statements, ecotopian discourse, and ecological economics) and construct a continuum of three human attitudes toward nature, from Nature as Object (the view of scientific objectivity) to Nature as Resource (the anthropocenic view) to Nature as Spirit ("mythic involvement with nature," or a deep ecological view) on a linear scale (Killingsworth and Palmer 2012, 11-12). Although they recognize that contemporary scientists are moving toward a more holistic model of this continuum, thus bending the linear continuum into a horseshoe in which Nature as Object and Nature as Spirit are brought closer together (Killingsworth and Palmer 2012, 14), despite that contention, the three major positions still generally place humans/culture outside of nature.

This constraining discourse of nature-culture separation persists whether humans approach nature as a measurable object, as a commodity, or as an emblem of the Divine. Yet for Killingsworth and Palmer (2012, 12), the Nature as Spirit pole is a position they insist brings nature and culture closer together, claiming for it "an identity in which the spirit of creation wraps the human and the nonhuman in an indissolvable unity with definite ethical consequences."

While Killingsworth and Palmer allude to this unity as fitting a monastic rather than a dualistic view of nature and culture, I suggest that their invocation of ethics and ethical consequences provides a humanistic binding to moral discourse and, as William Lynn (1998, 281) argues, gives us norms for "evaluating and directing our conduct . . . using principles about what is good, right, just, or of value." Rather than preRenaissance or, alternatively, "New Age" constructions of nature that 
hark back to monistic views of micro- and macro-cosmos using things such as the occult, magic, or astrology-or indeed, pre-modernist mindsets that conflated images, metaphors, and reality (Mills 1982)—Nature as Spirit views seem to invoke, rather, a mysticism that suggests a JudeoChristian sacred and "moral universe" in which good environmental decisions depend on human attributes of desire for doing the right thing (Pepper 1996, 125-26). ${ }^{4}$ Thus even as Killingsworth and Palmer suggest that Nature as Spirit has the capacity to bring nature and culture closer together, such a position is still bound by discourses of reason and anthropocentrism which suggest that only humans have the capacity to determine value and that such value is determined through moral reasoning about what is just or unjust.

A primary grounding of this schism between humans and nature can be attributed to the rise of the scientific method, primarily Bacon's development of inductive reasoning. Inductive methods move from scientific observations of nature out to generalizable laws, placing the human scientist in the position of control over nature and the purpose of science as having dominion over nature through observation and order. The resulting assumption is that "scientific knowledge equals power over nature" (Pepper 1996, 143). This underlying notion has played out contemporarily in humans believing that nature needs to be not only controlled but also managed - central values in both the modern environmental movement and modern industry. ${ }^{6}$ The connection of a scientific understanding of the world-in which nature exists only to benefit humans and its attendant notions of nature as a resource and progress as interminable and inevitable-remains pertinent to discussions of tree planting, as I take up later in this chapter. ${ }^{7}$

It is important to locate exactly where modernist conceptions of nature have led us, even as postmodern assertions that break down these bifurcations are clearly available. Scholars in the environmental humanities might consider, for instance, Donna Haraway's $(2008,159)$ assertion of nature as topos, a rhetorical commonplace, or Bruno Latour's (2004, 36-37) grouping of the natural and social worlds into assemblies and collectivities of human and nonhuman members that lend themselves far more easily to the inseparability of nature from culture. Yet even as contemporary scholarship may conceptually embrace the idea of natureculture, as Sarah Pilgrim and Jules Pretty (2010) point out, Western industry has not, remaining firmly rooted in notions of management, control, and progress. In addition, public environmental rhetorics have not accepted this position, as Killingsworth and Palmer (2012) establish. This is particularly true for English Canada, whose identity, as Catriona 
Sandilands $(2000,179)$ asserts, is enmeshed in histories of settlement, narratives of adventure, domestication, dominion over, and industrialized wilderness.

\section{WILDERNESS TROUBLE}

As William Cronon (1995) argues, wilderness and its associations, far from representing a place untouched by humans, constitute an entirely cultural construct as well as being a product of history, civilization, and-as others like James Morrison (1994) have noted-painful practices of colonization. Cronon (1995, 70-75; quotation on p. 71) points us to ways wilderness meanings have changed over time, moving from the connotive association with desolation, wasteland, barrenness, and terror in the eighteenth century- "the antithesis of all that was orderly and good"- to a romantic-religious association with power, sacredness, piousness, divinity, awe, and dismay by the first half of the nineteenth century. As he explains, by the twentieth century, much as a result of the works of John Muir, the piousness associated with a powerful and awe-inspiring wilderness was replaced with the domesticated sublime-associations with beauty, pleasure, and joy-as well as simplicity, primitivism, and a nostalgia for a waning American frontier, ideas circulated by the work of Frederick Jackson Turner (77). The last 300 years have witnessed a discursive "wilderness turn"-from desolation and terror to an appeal toward beautiful, "freer," and "truer" places that exist only outside the contamination of civilization, as "virgin" uninhabited land (79).

This turn created a number of cognitive associations in the public consciousness. First, as wilderness began to be associated with nostalgia and a diminishing frontier rather than dismay or fear, there was an increased push to preserve what was considered "wild" land-an emergence of a conservationist ethic in tandem with thoughts of wilderness. There was also an increased passion to seek out, find, and enjoy wilderness, not as a "site for productive labor . . . [or a] permanent home" but rather as "a place of recreation" to be enjoyed primarily by elites (Cronon 1995, 78). In a quest to mark off, preserve, and view wilderness as uninhabited, the move toward managing large parcels of land as national and provincial parks (as separate from productive uses of land) also continued the tradition of displacing and eradicating Indigenous peoples. This willful continuance of the European colonization of the Americas occured by "finding" land deemed "wild" and "uninhabited" and marking it either for development (as in first European contact with 
Indigenous peoples) or, later, "saving" the land for preservation or conservationist purposes (and often breaking treaty rights and Indigenous land claims to do so).

This ongoing displacement of people already inhabiting "wilderness" is noted in Cronon's discussion of Glacier National Park (which is still enmeshed in land claim arguments with the Blackfeet people), ${ }^{8}$ as well as in Morrison's (1994) discussion of Yellowstone National Park (which displaced the Crow and Shoshone peoples). Such a narrative is echoed by the creation of Algonquin Park in Ontario, which has a long history of rights claims with the Lac la Croix Ojibway people; Quetico Provincial Park in Ontario, which was created on reserve land of the Lac la Croix people; and Riding Mountain National Park in Manitoba, home to the Ojibway and Nakota/Assiniboine and site of a successful land claim by the Keeseekoowenin Ojibway people in 1991. Parks Canada (2016), the equivalent of the National Park Service in the United States, recognizes that the creation of Banff National Park in 1885 displaced the Stoney/ Nakoda people and acknowledges that no indigenous people were consulted in the creation of the nation's first seven national parks. ${ }^{9}$ The erasure of such histories of "wild" places as already inhabited, as Cronon (1995, 79) suggests, represents a "flight from history,"10 serving up visions and practices of wilderness committed to the idea of landscape emptied of civilizations and devoid of work, of the wild as separate from humans, as culture divided from nature.

This separation continues today, made manifest in common attachments to wilderness represented contemporarily in, for example, ecotourist literature. Aimed at the elite world traveler and crafted to situate wilderness as providing access to "wild" places, such messages about modern wilderness represent it as something unspoiled, pristine, remote, secluded, and "true" (Black and Crabtree 2007, 491). Yet as Cronon's work reminds us, contemporary views that privilege an "authentic" wilderness experience are still very much a situated, humanmade construct that ignores hundreds of years of material and discursive changes ${ }^{11}$ — creating a very real divide between what counts as "nature" and what doesn't- and continues the bifurcation between culture and nature. This is perhaps nowhere as true as in Canada, a place in which wilderness is seen as a marker of "national specificity" that routes desire through stories of origin and universal national experience through narratives of non-domestication and deference, ${ }^{12}$ despite the fact that 17 percent of the country's GDP is produced from its natural resource sectors (mines, forests, and oil $)^{13}$ and another 6 percent from agriculture (Agriculture and Agri-Business Canada 2014). ${ }^{14}$ 


\section{"THE ENVIRONMENTAL DILEMMA"}

A term like environment, taken broadly, gestures to a situated being-inplace, an awareness of surroundings for descriptive, analytic, and meaning-making practices. However, environment broadly conceived has also been subsumed under environmental meanings: as David Harvey $(1996,118)$ suggests, this is a convention that relegates discussions of environments either to "the relationship of human activity and well-being or to $(a)$ the condition or 'health' of the biome or ecosystem which supports human life, $(b)$ specific qualities of air, water, soil, and landscapes, and $(c)$ the quantities and qualities of the "natural resource base' for human activity." Such a distinction that classifies human activity on the one hand and the ecosystem on the other is a common basis of the nature-culture divide, one that has been solidly critiqued, given that ecologies without human intervention are impossible to study and become arbitrary and ideological rather than objectively "true" (119). Yet embedded in definitions of the environment, environmentalism, environmental issues, and environmentalists are limiting narratives of humanbased economic progress, technology, and development (the "natural resource base"), on the one hand, and ecological preservation on the other. Such a view pits Western liberal individualism (in the form of the "self-made" human) against "environmental values" that privilege protection and conservation of natural spaces while ignoring the very real ways natural spaces propagate and house particular technologies, labor, and infrastructures.

As Samuel Hays (1987) points out in his historical study of public environmental awareness, the development of environmental values-even preservationist ones-has always had economic roots. With a rising standard of living after World War II, Western concerns about the environment became transmuted into a concern for an elite environmental quality and was far more concerned about consumption and the construction of an additional "amenity" to be added to consumer life than about any sense of being-in-place (Hays 1987, 34-35). Expectations of a higher standard of living go hand in hand with an ideology that purports that an improved quality of life is accompanied by clean air, less noise, drinkable water, pristine recreational areas, and pollutantfree waterways in which to fish or kayak. Despite consumerist leanings that construct the environment-as-amenity (and thus worth preserving as a resource), such a position still establishes an "environmentalistdevelopmentalist" divide (Hays 1987, 9).

In this dichotomous setup, environmentalists "who seek long-term protection of endangered environments regardless of short-term economic 
costs" are pitted against developmentalists "who seek short-term economic gain regardless of long-term environmental costs" (Hays 1987, 9). This "good-guy"-"bad-guy" mentality not only presents an oversimplification of the fact that the system in which we live "produces both economic prosperity and environmental pollution" but also positions those without economic interest in the natural world ("environmentalists") against those who have such interests ("developmentalists") (Hays 1987, 9). ${ }^{15}$ It leaves no space, then, for the worker with a clear economic interest to engage in what might, in other circumstances, be termed a "preservationist" act. The impediment of such binary thinking exists as more than only a theoretical problem; it simply doesn't describe or make sense of well the experiences those with a great deal of exposure to fragmented natural spaces actually have. Environmental studies scholars term the perceived incommensurability between these poles of unchecked growth and preservation a "dilemma." 16 And this sense of having two equally unfavorable choices from which to choose characterizes much of public environmental discourse. Yet on the local level, in focusing on the inhabitant - whether human or nonhuman-our attention may be drawn instead to the conflict and complement between, the middle way of being. Such a middle way has been embraced by both ecological postmodernists and material ecocritics; however, in drawing attention to a new materialist environmental rhetoric, I underscore a lens that inherently seeks to frame the suasive forces between preservation and growth. Until we recognize that the polarity between growth and preservation underwrites both rhetorics of efficiency (developing more efficient ways of using physical resources) and consumer consciousness (ensuring a quality of human experience that privileges pristine, untouched, and beautiful surroundings) in the very discourse of environmentalism, ${ }^{17}$ we foreclose the possibility of developing nuanced forms of understanding and producing human attitudes toward the environment.

\section{HUMANISM, EFFICIENCY, AND INCONSISTENCY: GEOGRAPHIES OF PLANTING}

From historical ideals of nature that exclude humans while creating it as a measurable object to the domination of modernist scientific worldviews that construct a mechanistic and rationalistic view of the material world, contemporary discourses of nature have, as Max Oelschlaeger (1991, 96) contends, left us with a nature converted "into a standing reserve possessing market value only." This constructed view of wilderness a-historically separates preservationist ideals of "untouched" wild 
land from already inhabited land, filled with biota and abiota, already teeming with productive uses. This gears human attention toward managing its treatment and development. Modernist notions that place humans in a position of control over their environment and position environments as no more than resources to be protected or exploited by humans have clearly taken hold as the most common discourse about the nature-culture relationship in contemporary life. ${ }^{18}$ Separations of self/other, human/nonhuman, and developmentalist/preservationist are continually positioned against a backdrop of unending progress and technological advancement. The ways people have historically taken up these topics are central to understanding how pervasive both rhetorical humanism and rhetorics of efficiency are in characterizing what one might say about the environment, about nature, or about wilderness, and they similarly direct our attention contemporarily within the context of industrial forestry. If nature-out-there is only something to be managed and controlled by humans-in-here, this not only prohibits seeing humans as always affectively entangled with things and nonhuman others (for example, bacteria, food, chemicals, or animals) but also prohibits possible disruption of these discourses in favor of simplistic humanistic models of agency and persuasion.

Anna Tsing (2015a) draws our attention to patchy areas of the Anthropocene through the figure of the plantation, which she defines as "ecological simplifications in which living things are transformed into resources, future assets, by removing them from their lifeworlds." It's easy to see the world of the cut block, where tree planters live, work, and sow, through the figure of the anthropocenic plantation, complete with Tsing's assertions of the cultural work of alienation required to make resources out of living things-that is, trees to eventual lumber, pulp, or paper. Yet in bringing forth the plantation as a marker of the patchy Anthropocene, Tsing (2015a) notes that everywhere plantations are formed, they emerge through "vernacular histories, which tie them to the contingencies of encounters and the peculiarities of place," noting that plantations' proliferation "depend[s] on the multispecies assemblies they simplify." For Tsing and for the accounts I give throughout this book, places like cut blocks and those who do cultural work within them help us understand the Anthropocene as both an environmental dilemma and something that is only ever invented and enacted in place and through relations-as Tsing (2015a) has it, only ever "parochial, perspectival, and performative." Taking together the discourses we live and work within and the tensions they create on plantation landscapes also push us to more closely examine perspectival descriptions that 
emerge from them rather than to merely take for granted simplified rhetorics of efficiency or humanism. It is worth extending an examination of such performances to understand the Anthropocene not only as global but also as existing in the tension between simplified ecology, on the one hand, and the particularity of experience and multi-species assemblages on the other. If the Anthropocene can be invented, we can also reinvent it.

While tree planters creatively make space for the ambient and material in their narratives, they are also caught up in specific relations of selves to nature that are bound by modernism and yoked to notions of individual choices and industrial progress-the cultural work of alienation, as Tsing (2015a) might suggest. Tree planters are representations and disseminators of the anthropos, and as human actors they are enabled by and constrained in their discourse choices by what has come before them. Still, while it is "not easy to say something new," as Foucault has it, it is also not impossible to do so. In everyday vernaculars that depend specifically on place, planters give voice to everyday possibilities for imagining humans as enmeshed in lifeworlds that are articulated not only in terms of inevitable progress or individual choice but also in terms of persuasive nonhuman selves, affects and intuitions, and interactions with things. Such an argument relies on seeing planter descriptions through the lens of a new materialist environmental rhetoric, in which tensions between these seemingly incommensurate positions become generative sites of encounter. In the next sections I discuss how planters' discourses are caught up in rhetorics of both humanism and efficiency, which lay the groundwork for understanding geographies of planting in particular located ways in subsequent chapters. In them, you'll encounter descriptions of tree planting by planters whose voices make up the bulk of this book: Lindsay, Ryan, Tamir, Georgia, Dan, Sam (Dyck), Nik, Sam (Friesen), Thomas, Thayer, Ross, Luke, Erin, Jane, James, and Jon.

\section{RHETORICAL HUMANISM}

While it is not the aim of this book to qualify all contemporary and historical debates about rhetorical humanism, ${ }^{19}$ humanism's main tenets-an emphasis on human beings; on reason; on individual freedom, choice, and autonomy; on a desire to increase human happiness and on that happiness as the only "good" - are already privileged in discourses about nature that position it as an object, favor scientific rationalism and decision-making based on knowledge and reason, and 
seek to preserve nature for the purpose of either future resource use (production) or gratifying human experience (profit). In this bifurcated view that characterizes the discourse, human choices about nature become, as Thomas Rickert (2013, 251) puts it, "ultimately subjective event [s] played out against an objective world." Here I frame the pervasiveness of humanism in tree planters' narratives as rhetorical, or, as Timothy Laurie $(2015,144)$ maintains, "humanism as a narrative about humans." The fact that planters appeal to humanism as they negotiate topics within their experience is a marker of anthropocenic worldviews; however, they simultaneously challenge such a binary framework by their inconsistencies. Such disruptions and messiness suggest vernacular alternatives to privileged binaries-places of fragmentation that request different kinds of attention because they are fractured with unreason, nonhuman resurgence and agency, rhetorical bodies, and sticky affects. I argue that paying attention to these patches of unreason works to resist the simplification that comes with the nature-culture split inherent in humanism and efficiency.

Attention to how these binaries function in common planting themes is initially necessary to demonstrate the suggestion that planters use common notions of humanism rhetorically - that is, for certain means and to particular ends. As they discuss their work, they set up a particular geography of planting that situates the human as a central element of the anthropos. This is perhaps nowhere more apparent than in planters' descriptions of the job itself and their visions of themselves as individuals, as well as in how they describe their "pieces"-what they term "good" and "bad" land.

\section{"So You're a Dirtbag?" The Prevalence of Individualism}

Although tree planting is based on some communal experiences-planters live together in "bush" or "isolation" camps in groups of thirty or forty, where they share meals and evening hours for a three-month season-it is generally a job characterized by a great deal of social isolation and exposure to long periods of time people-free. As in this chapter's opening narrative by Kailen, a tree planter who took part in John Bodner's 1998 ethnography "Slash Romance," these experiences are encapsulated in moments-that is, "when Eric left me on my piece of land and said, 'plant' and walked away." A tree planter spends his or her ten- to fourteen-hour workday planting trees after being dropped off by bus or truck (within a two-three-hour drive of the planting camp) or helicopter (for longer distances). Although planters occasionally work in 
pairs separately on one large parcel of land (a "piece") and a planting contract's work will occasionally be assessed by a foreman, a planter generally works alone. Because of this, planters situate their work on highly individualized terms, which resonates with rhetorical humanism's emphasis on autonomy and personal responsibility. As Georgia, a planter with two years' experience, describes:

I think, well, the thing about planting trees is that planting 1 tree isn't physically hard at all. It's like, anybody can do it. But what is hard is planting, you know, 300 trees and then doing that over and over and over again. And so, it's almost like more mentally challenging than physically challenging in some ways. Because it's like, you know, just planting that 1 more tree isn't hard, but you just have to convince yourself to do it over and over and over again. And there's like, you have kind of like a boss, like you have a foreman that comes by once in a while, but they're not there to make you do anything. If you don't want to plant no one is going to make you plant; you can just lay there all day if you really wanted. And so it's really just about convincing yourself to do it, and after like sixty days into the season it gets much harder, and so it's just like this constant mental game of like, "How I am going to convince myself to plant 1 more tree and then 1 more box of trees and then 6 more boxes of trees?" And, "How am I going to convince myself to get up tomorrow and do that?" (G. Chappell, unpublished data)

In Georgia's description, she captures both the nature of the work-grueling physical labor-and the laissez-faire approach taken in the job itself: no one will make you work (since individuals get paid per tree), yet the work needs to get done to fulfill the obligation of the contract agreed upon by the tree-planting company and a logging company to plant a particular block of land in a certain number of days with a certain number of trees. Tree planters often connect the motivation needed for the job to an individual work ethic. As Luke, a two-year planter, says: "The thing about tree planting is if you put a lot of work into it, you are rewarded because you're getting paid per tree, so you're getting rewarded based on how much work you put into it rather than another job where you could put, say in construction, where you could work harder than everyone else, but you'll still get paid the hourly rate. Where [with] tree planting it's really based on how much you put into it, you're getting out of it" (L. Rempel, unpublished data).

A similar sentiment was echoed by Tamir, a four-year planter, in attributing value to being a "self-starter": "Self-starting, you know, because you're on your own out there, no one helps you, even your first year it's sink or swim" (T. Bourlas, unpublished data). Thus the geography of planting, despite being embedded in a reforestation collective of other 
planters, foremen, supervisors and logistics coordinators and "checkers" (quality control staff), camp staff (e.g., cooks), contract negotiators, logging company clients, and the government, is boiled down in treeplanting accounts to an individual endeavor dependent on motivation. To tree planters, it amounts to individual choice, as Sam, a four-year planter, suggests: "Your time is your own. Obviously, you're encouraged to plant as many as you can, but if you feel like taking a three-hour break, you take a three-hour break, and, I mean that's really, you're losing out, you're losing out on probably, you know, close to a hundred bucks by doing that, but it's all your own choice really" (S. Friesen, unpublished data).

Similarly, those who choose to plant trees are understood within the community to be a certain type of individual. As Sam, a five-year planter, reports, "there are various types, sort of the young people trying to either earn some money or escape from something" (S. Dyck, unpublished data). This theme is often taken up by other planters in the data when they describe why they chose a job planting trees. Tamir, speaking of his first year planting, said "it really freed me from my parents, really freed me from having to go to school, having to get a real job" (T. Bourlas, unpublished data). Planters I spoke to often described themselves as loving adventure and challenges. Erin, a threeyear planter, had "a tendency to try and challenge myself, pick things that are hard and just go for it" (E. Sawatzky, unpublished data), or, as Sam suggested, there was value in "pushing myself beyond the limits I think I have" (S. Friesen, unpublished data). Often, a reflection on the experience of planting became a narrative of growth and improvement stemming from hard work, represented by Jon's (a one-season planter and two-season logistics coordinator) sentiment: "I got challenged a lot, and I learned that I could deal with problems and overcome them, the 'adapt, improvise, overcome' kind of philosophy" (J. Sprohge, unpublished data). Here we see an emergent humanistic value on individual freedom: to make decisions, to live unbounded by the expectations of others, to address challenges and overcome them by adaptation, creativity, and improvisation. Taken together, these accounts are clear descriptions of the importance of the individual spoken through narratives of choice, motivation, personal responsibility, and freedom.

Humanism, for tree planters, is also realized through character and veracity. Planters consistently value integrity, decrying stashing, or hiding or throwing away trees-as Sam noted, "it would be really easy to just throw a bundle of trees over a cliff and just make your money that way" (S. Friesen, unpublished data)—but a responsible individual 
does the right thing. Yet this sense of personal responsibility is not simply attributable to personal integrity, attitudes of sink or swim, or the development of a simple entrepreneurial self. The pervasiveness of humanism through descriptions of individualism is complicated by companies' policies of planting, pay, and organizational structure that depend on a particular planting speed, as Lindsay (a single-season planter) suggests:

I think the first, was it the first two week[s] or first two shifts or I don't know, for a set amount of time at the beginning they would just top you up [to minimum wage] and it was fine, but after a while, after the grace period was up, they'd still top you up, but it would start coming out of your foreman's paycheck, and then it would start, after a little while, it would also start, some of it would also come out of your supervisor's paycheck, and so that was the part that bothered me because I was like, why should they have to pay for me being slow, you know, when yeah, that's just not fair to them. (L. Ainsworth, unpublished data)

Here, Lindsay describes incentive to work that is not based on getting paid a particular wage or simply attributable to her penchant for hard work. Rather, the responsibility of an individual to make choices and to do what is reasonable and ethical depends here on the other-to not make someone else suffer by your own hands. For a second it is possible to glimpse the crack in the assumption of the neo-liberal individual, humans not reduced to naive victims of neo-liberalism or the simplification of the "autonomous chooser" (Fitzsimons 2002). It is true that planters are workers, and their aims are entrepreneurial in nature. Yet such self-reflexivity as noted in Lindsay's narrative suggests a tension between personal choice and individual progress, on the one hand, and egalitarianism on the other. The presupposition of the value of humanism-personal happiness-is always situated in a particular landscape and historical period and with complex vernaculars and material relations; as I take up in later chapters, it is not such an easy simplification.

Elements of tree-planting work are set up to value the individual and the subjective choices he or she might make, since there is no technical minimum requirement of per-day planting, little oversight, and long swaths of unstructured time. Tree planting sets up for those who pursue it a particular narrative of individualism: freedom to make choices about when to work, how much to work, and whether to "cheat" the system. Tree-planting discourse sets up a particular narrative about humans: that each is an individual with the freedom to do as he or she wants, that each has a choice about whether to work hard, that those subjective 
choices are played out in an objective field. This is further instilled in planters' consciousness by their community-commonsense interpretation of silvicultural work as the "bottom of the totem pole" (G. Chappell, unpublished data), the "bottom of the industry" (S. Dyck, unpublished data), or the "bottom of the hill" (R. Boldt, unpublished data) of forestry work. In many ways, the narrative plays out as an underdog individualism, acceptedly self-branded-much like contemporary consumer trends-by "external disadvantage, and passion and determination" (Paharia et al. 2011, 775).

Yet this pride manifests itself in unusual ways, as James, a ten-year "veteran" planter, says: "You start to think of yourself, or you get either the reputation that comes first or you start to think of yourself that way or you think of yourself this way, and then it's a self-fulfilling prophecy. You think of yourself as a dirtbag, basically. I think dirtbag is the term most of us use to describe ourselves, fairly proudly, about living in a nonconventional way" (J. Simpson, unpublished data).

While James reflects on the pride of accepting an identity of a tree planter that embraces the unconventional, he uses the nonhuman vernacular dirtbag to describe such an identity - which could be substituted with a more common humanistic term such as migrant worker. The term usually means an "unkempt or slovenly person," yet such a reference is derived etymologically from "actual bags of dirt"-originally, sandbags or vacuum bags in the United Kingdom (Martin 2017). Planters embrace both ways of thinking; being a dirtbag is both living with unconventional employment rhythms and also getting comfortable with "just having dirt on you all the time" (R. Boldt, unpublished data). Such terminology saturates and disturbs the easy distinction between the human and the nonhuman and between economic and natural paces; as an article written about British Columbia's artist-dirtbags (Johnson 2016) hints, the two inform each other. As freelance illustrator and tree planter Max Brown explains, "Artistic people are attracted to planting because they need to pay their rent and student loans, and they likely aren't doing that by selling art." However, Brown simultaneously builds on this simplification, saying that "the [art] I'm doing now that uses repetition techniques is pretty much directly inspired by the way pieces of land are planted" (quoted in Johnson 2016). The dirtbag human is rife with possibilities: covered in organic matter, using movement and exposure to nonhuman elements to construct a self through interaction with what Jane Bennett (2010, xvi) might term vibrant things, moving agentive and persuasive capacity from the individual toward a collective of human and nonhuman. 
"Cream" vs. "Slash": Good and Bad Land

A common element within tree-planting vernacular is an assessment of the land workers plant on and that land's attribution of either "goodness" or "badness"- traits given to the land, but also properties that bleed into planters' assessments of their work, their feelings, their days, and what differentiates one from another. Here the attributes of "good" or "bad" are descriptive both topographically-qualities of landscape-and also evaluatively and affectively, how happy or unhappy the land makes the planter. That is, planters describe land in humanist terms that treat happiness as "the only good" and the desire for greater happiness as a primary motivation-whether it makes their job easy or difficult and thus whether they labor for more or less financial gain at the end of the day. In other words, they qualify the land based primarily on whether it makes their own lives better, with a few exceptions.

In terms of planting geography, "good land" "means it's a bit more environmentally decimated":

Some logging companies will come in and will clear-cut most of the trees but will leave a lot of the, a lot of stuff standing, will leave bushes and alder bushes and trees and will leave all the logs on the land that they've cut that they don't want, which means that the land is able to come back to its natural state more easily but [also] means a lot more work for us. We're jumping over logs and climbing over things, and, especially if it's slippery, you're scrambling and falling and getting caught in alder bushes who knows how many times. Whereas other companies will come in and they will just clear-cut the whole thing, take everything, drag it into the center, and burn it, which means that it's a really nice piece of land for us to plant because there isn't all kinds of stuff to be climbing over. (E. Sawatzky, unpublished data)

All of the planters I interviewed differentiated between good and bad land by describing its characteristics in vernacular terms: "The name of good land is 'cream,' that's if you get 'creamy' land, that's the best. And so like, at least in the area we've planted, it's kind of different everywhere, but like, the definition of 'super creamy piece' would be if it was basically just dirt because a lot of what you're planting in is . . like, it's been forested, right? And so there's stumps everywhere and then between the stumps there's sort of like-they call it 'slash'” (G. Chappell, unpublished data). All of the planters I spoke with made the distinction between good and bad land by tying it to both their progress and the preparedness of the land through machine-human intervention. As Ryan described, "There's just so many different variables, but in general soft land without any dried debris on top is good land, and hard, clayey baked land where there's tons of like little sticks ... or if there's tons 
of fallen logs which you have to constantly step over and stuff like that, that's bad land. Basically, anything that slows you down is bad, and anything that allows you to go fast is good" (R. Boldt, unpublished data).

Although the fast=good and slow $=$ bad equation sounds simple, the algebra involved was composed of complex descriptions of micro-sites that were created by machine preparation and dependent on soil type and topography. Planters were more than willing to describe land types based on preparation. Ryan further elaborated on three main types of cut blocks that determine a planters' experience of the land: prep blocks, direct blocks, and fill blocks. Prep blocks (another word for scarified land), noted overwhelmingly as the land most likely to be creamy, are those in which forested land is cleared by machine with little scrub or brush left in the way, either through digging large or small rowed trenches, scooping large holes in the earth and upending them into mounds on which planters plant their trees, or burning debris to provide cleared terrain and ashy soil (T. Kroeker, R. Boldt, L. Ainsworth, unpublished data). Direct blocks are those in which varying amounts of unusable debris ("slash") or significant layers of "duff"- "mossy, crumbly stuff that wasn't soil” (S. Friesen, unpublished data)-have been cleared, leaving debris either on the forest floor to decay or amassed in large piles (see figure 1.1). Fill blocks are those areas of deforested blocks that have been previously replanted but whose rates of growth are too slow and therefore they must be replanted, a kind of "failed block" for logging companies that seek to avoid penalty. Fill blocks are often the most challenging because planters are fighting through regrowth (R. Boldt, unpublished data).

Yet scarification was not the only factor in determining good land; planters determine land's goodness by its easiness to negotiate bodily, either in terrain attributes (flat vs. mountainous) or soil quality (organic vs. inorganic). Planters overwhelmingly described flat terrain as the best for planting (usually available in prairie provinces like Saskatchewan and Manitoba) and mountain planting (primarily in British Columbia or Alberta) as more challenging:

You've got really steep topography or relief or whatever, and the forestry companies there had an idea that they needed to shelter the seedlings from the Chinook winds because they warm them up prematurely in winter, and they would leave them unexposed or something like that, so we had to, so we would have to plant them at a certain directional orientation relative to like an obstacle of some kind, like a chunk of wood or like a mound of dirt or whatever that just happened to be there, which is a huge headache, as you can imagine, and slowed you down considerably. It was 


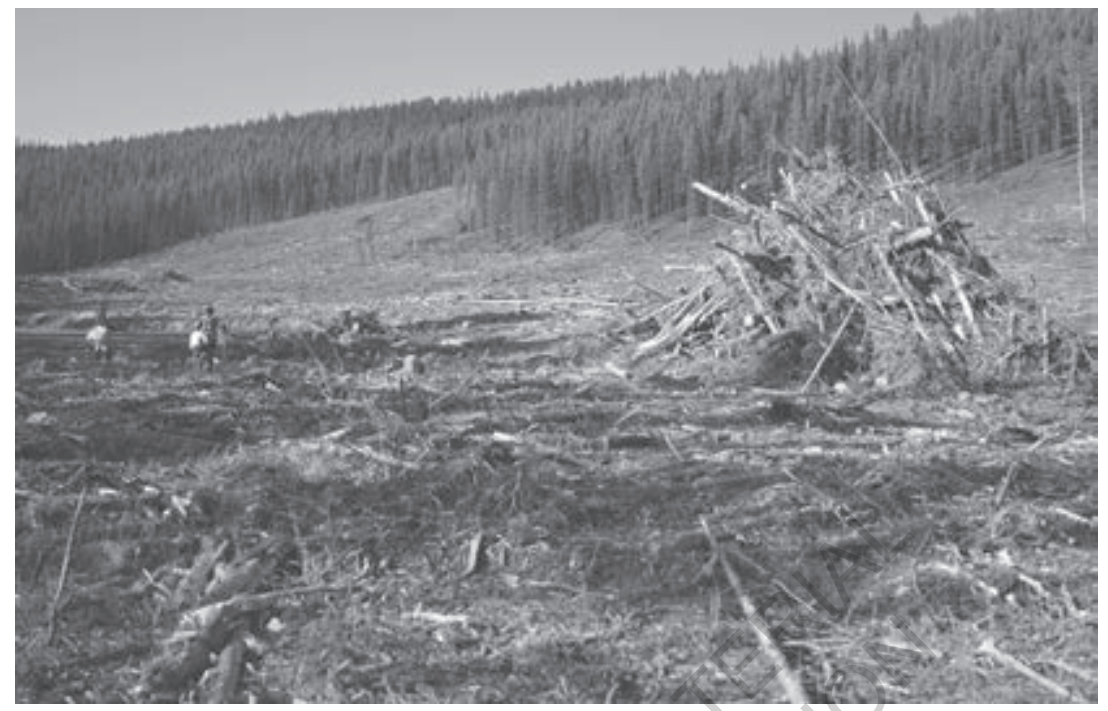

Figure 1.1. Slash pile (Photo credit: Lindsay Ainsworth)

like you had to always shelter them from the southwest or something like that, I forget. Yeah, obviously really different because you're in the mountains, so it's like sometimes you're on, you know, I don't know, I probably a few times was on like a forty-five-degree angle, that would be pretty steep but that could happen sometimes. (T. Kroeker, unpublished data)

Georgia elaborated on the difficulty of mountain planting:

You're in great shape if the slope you're planting on is the same direction you're supposed to be sheltering the trees-because if the slope is here and [the] tree is here [motions downhill] and then just the slope itself protects the trees, but I was planting on a very steep mountain that was also on the exact opposite direction I was supposed to shelter the trees from, so I had to find obstacles twice as big, and so I was basically like, it was just like rock in most places, rock with like a couple of inches of dirt on top of it so you couldn't tell where the rock was. And so, and there, there was no natural-there was no way to get your shovel deep enough to dig your trees in. So I was building little tipis for my trees to live behind. It was pouring rain, thunder storming all day. I was having a terrible time. (G. Chappell, unpublished data).

Topographic difficulty is compounded by soil type, as Nik, a three-season planter, described:

Bad land is, well, we had lots of different kinds. So, swamp, I mean, that's just, the problem with that is just not a lot of good soil. A lot of what you can plant in is sphagnum moss, which is like, it's like a sponge basically, and you can plant in it, it's just, sometimes it's really thin, so you can't 
squeeze a tree into something that['s] the depth of the pod, which is typically 2 to 3 inches, [it] won't fit into [the soil], or you'll fail your assessment. And other times with the swamp it's like, it'll look like it's solid, but it's not. So I used to wear rubber boots, but even once in a while you'd get a full leg in, and it's tough. It's just tough to get a good groove going. The best land is somewhere you can just, it's called "pounding," so you go, you know, head down, you just get into a good groove, you just, tree, tree, tree and you don't have to switch direction too much; you don't have to deal with too many obstacles. Some other bad land is rock top [cap], so it's just basically like an inch of soil with rock underneath, and that's just the worst 'cause you're slamming your shovel down, and you feel that come up your arm, hurts, and you just can't get trees in. So you're going around trying to squish little pieces of moss together; it's just futile.

In my second year, we dealt with this land called "chemical." So basically a plane flies overhead with a selective herbicide, and it kills everything, all the big leafy stuff, and then you go through and plant. But the problem is that it hasn't been mowed down, so I think mostly what they use it for is land that was clear-cut years ago but wasn't planted right away, so just random things, like natural forest, would regrow, but they're trying to have like an optimum spruce stand. So they go ahead and spray if after it's been growing for five to ten years, so you have [dead] trees that are like 6 feet tall, 4 feet tall, 2 feet tall, just a big mix, and planting through that stuff is just, the first time I hit that I was so choked, I was like, how am I supposed to [plant]. 'Cause you're just dodging trees, you're getting trees in the face, and you can't really, it just feels futile. There's all these dead trees, you're going through a dead forest, crazy. But yeah, there's all kinds of bad land. When it's all water, that's the worst though 'cause you're like, can I please not plant this? None of these trees are going to live anyway.

(N. Friesen Hughes, unpublished data)

Thus the evaluation of land, its preparedness for planting, has little to do with how well the trees will fare, how optimal the land is for forest regrowth, or how ecologically viable it is. Instead, land is schnarb if it is difficult (T. MacInnins, unpublished data) and creamy if it is easy and allows a planter to move quickly and without fear of injury and, above all, if it allows a planter to "pound"-to get as many possible trees in the ground at the quickest possible rate. In this discourse, we see some accepted premises of the separation of nature from culture, whether in Nik's separation of "natural forest" from "optimum spruce stand" or Georgia's undisturbed mountainside contrasted with constructed tree tipis. No matter this reification of the nature/culture split, planters commonly see themselves - that is, humans-at the center of land evaluation; that is, land as an object is good or bad only in relation to the human subject planting on it.

Perhaps this is no more clearly evidenced in planting descriptions than when tree planters ascribe ownership to the planter, as Kailen 
does in the epigraph at the beginning of this chapter. All planters interviewed at one time or another described their work as working on "your piece" (G. Chappell, L. Ainsworth, R. Boldt, T. Bourlas, unpublished data) - that is, whether in statements like "I was out of land" (S. Dyck, unpublished data), "I had a good piece" (R. McCannell, unpublished data), or "everybody gets their land" (D. Cheater, unpublished data), planters view the land they are on as representing a kind of temporary ownership. This resonates with traditional notions of humanism and agency that place humans at the center of the narrative and, in this case, nature as exterior to it, as something that may be owned and transferred. Yet there is some complication in planters' evaluation of their land. Throughout their descriptions, we see the intersections of planters with things: machine mulchers, tractors and tows to create scarified rows (like bräcke mounders); planes filled with herbicide; shovels to pound with. We can't fully understand the geography of planting without also looking at the intersections of planters' relations with the nonhuman. Before I examine those relations, however, it is worth examining the intersections of humanism with rhetorics of efficiency built into the economy of tree planting, which depend on similar reasoning and logic.

\section{RHETORICS OF EFFICIENCY}

There is a clear connection between the humanistic, happiness-seeking individual focused on the rationality of subjective choices promoted by planters' discursive choices and the rhetorics of efficiency, which are focused on an economic model of increased production as the definitive "good." As Thomas Princen (2005, 49) details, although we generally conceive of efficiency as a commonsense principle that has to do with a simple "calculation of output per unit of input," its relegation to a strictly economic notion of energy and outcome has been a modern revision from efficiency's classical roots. As Princen notes, the Aristotelian notion of efficiency had embedded within it principles of desire, planning, materials, and effectiveness and was concerned primarily with the fit, appropriateness, and effectiveness of the taskmaster and the task environment to the task-importantly, Princen $(2005,51)$ observes, not with the speed or cost of the labor involved in carrying out the task.

With the advance of mechanized industry, "effectiveness, goal achievement, the neat fit of means and ends slipped away as numbers were invoked to measure, indeed, define, efficiency ... Efficient solutions to 
problems of production are [now] those that improve a benefit-to-cost ratio for producer or consumer. An economic efficiency lowers the cost per unit of output, without sacrifice of quality, in relation to the value or price of the finished article" (Princen 2005, 52).

Princen attributes Adam Smith's Wealth of Nations and the scientific rationality circulated by engineer Frederick Winslow Taylor as central to modernist underpinnings of the "economic man" and the rise of the corporation, which together successfully changed the meaning of efficiency from effectiveness to "nearly synonymous with 'productive,' or 'useful,' even 'good'" (Princen 2005, 50) and a singular notion of labor efficiency as "the shortest possible time for each job to be computed and fixed" (Princen 2005, 59). Yet Princen's work reminds us that this change has been a more than 200-year process in the making that has modified efficiency to not only a singular economic principle but also a social one-what it means to be a good and useful subject. In part, this was a result of the invention of an idealized "economic man," created by economists, a "hyperrational human who bases all decisions on perfect information to maximize personal gain" (Princen 2005, 55). In other words, a human who doesn't exist.

While this definition clearly resonates with the crux of the anthropos, in which there is no greater good, perhaps, than (hu)man maximizing personal gain, Princen also points out that the notions of personal gain and profit motives are modern ones by the standard of historical economists such as Robert Heilbroner (1953, 22), who notes that, although "ubiquitous," such a way of thinking is "as modern an invention as printing" - that is, it comes with a contextual and emergent history and may even be considered relatively young. Thus, while I attend to the ways tree-planting narratives similarly adhere to modern economic and social principles of efficiency, it is important to keep in mind two tenets of contemporary efficiency models that work to reify separations between nature and culture: (1) efficiency's imagined agent/actor as an impossible, perfectly informed, "hyper-rational," gain-seeking, pleasuremaximizing human; and (2) the purposeful construction of mechanical efficiency as created to separate skills from knowledge or "thinking from doing" (Haber 1964, 23-24). These separations are enabled by anthropocenic views of nature as a resource that hinder both dwelling perspectives (which denounce the split between mind and matter, thinking and doing) and human-nonhuman assemblages-"ad hoc groupings of diverse elements" (Bennett 2010, 23). As later chapters show, both of these hypotheses are patchy at best when viewed through an ambient perspective. 
The Money Function: Nature as a Resource, Trees as Capital

In discussing the capitalistic values embedded in contemporary conceptions of environmental and ecological debates, David Harvey (1996, 150) argues that current views on nature (which he seeks to disrupt) rest similarly within economic thought: "It appeal[s] to the theory of markets, to the goals of maximizing utility, and to the centrality of money as the common means to measure heterogeneities of human desires, of use values and of elements and processes 'in nature.'” Importantly, Harvey (1996, 150-51) notes that this discursive approach to valuing nature is conducted almost exclusively through speaking in powerful and universal "money terms" in which a particular natural resource-cumcommodity is attributed a particular monetary value.

Planters certainly embrace the notion that nature can be measured and spoken through the language of money, which accompanied their discussion of good and bad land almost exclusively; as Sam noted, "usually, the standard reference is financial" (S. Dyck, unpublished data). Planting decorum at camp makes it poor form to discuss how many trees a person planted during a day; planters repeatedly noted to me that to disclose their tree-planting numbers on a given day is tantamount to tackiness, rudeness, and vulgarity. Yet planters had little difficulty talking in explicit numerical terms without prompting during the interviews. Contemporary notions of efficiency are concerned, as Mary Clark (1989, 275) argues, "only with what can be counted . . How much? How big? How many? How fast? How long?" An interesting tension is thus revealed when a social injunction against talking about money is the standard of decorum in silvicultural work, yet planters are keenly aware of their numbers every single day they plant-pointing perhaps to the insidiousness of efficiency as an organizing logic of work, as a selfmeasure of the neo-liberal individual.

Planters would talk specifically about something they called tree price, which, despite the misleading name, means the money a planter makes per tree (not what a tree "costs" to either acquire or grow). Tree prices ranged from ten to twelve cents per tree on easy, scarified land (S. Dyck, L. Rempel, unpublished data), twelve to fifteen cents per tree on direct blocks (Boldt, unpublished data), and "twenty-five to fifty cents, something like that, depending on how hard the land is" (J. Simpson, unpublished data) in fill blocks, mountainous areas, and boggy land. As I spoke with Tamir, who mentioned during an interview that there were "summer" and "spring trees" (in my mind denoting tree type), he quickly clarified that "summer trees are, they're summer contracts, so, you know, you sort of bid on your spring trees, and they're sort 
of worth a certain amount, and many companies don't plant summer trees. Summer trees are generally in industry looked at as lesser paying, larger growth in the block ... But the trees themselves are the same, but the contracts aren't as good ... the tree is the same ... It's sort of the name given to the contract" ( $\mathrm{T}$. Bourlas, unpublished data).

Tree price is the capital system by which all other numbers that interest planters are tallied; it denotes land price (i.e., "twelve-cent land") and even season (spring or summer). To this end, when planters talked about their experiences in numerical terms (a cornerstone of contemporary efficiency rhetorics), they did so with the underlying notion of tree price as the foundation of their narratives and a clear sense of the driving economy of the forest industry. As Jon articulated, "The government charges X-money per stump that the, it's called a stumpage fee, that the logging companies pay to cut in an area, but when combined, when you look at that stumpage fee versus the cost of growing the seedlings and paying the replanting, it's not balanced at all" (J. Sprohge, unpublished data).

Harvey $(1996,152)$ provides a detailed critique of valuing nature in this way, recognizing the constructed, volatile, and unreliable nature of the money system. He locates this critique in Marx's views on money as a social representation of "labor time and price" rather than a meaningful or steady representation of value, pointing out the unreliability of various money measures in world currencies and indicating the arbitrariness of assumptions that guide money terms. Harvey notes the problematic assumptions behind money prices being attached to particular things independent of their ecosystems (i.e., "we presume to value the fish, for example, independently of the water in which they swim") and notes that the linear, Newtonian temporal structure of valuation (i.e., discounting prices over time) does not fit with non-linear, idiosyncratic, and glacial natural paces (Harvey 1996, 153). This is particularly the case with tree planting, whose measure in cent-value per tree (as separate from the substrate that grows it) has nothing to do with the botanical timescale (the eighty years it will take for a pine tree to be harvestable). Such a skewed appeal to money-based valuations, Harvey $(1996,154)$ argues, "condemns us to a world view in which the ecosystem is viewed as an 'externality' to be internalized in human action only via some arbitrarily chosen and imposed price structure or regulatory regime," further entrenching the nature-culture divide by positing the external natural world as a resource (as in the case of a ten-cent tree and a twenty-five-cent tree being exactly the same tree). Even as planters keep track of their work by tree price, they also recognize the arbitrariness of the money system, 
whether by commenting on tree-planting companies' underbidding on challenging topographical contracts or logging companies' purposefully ignoring environmental protections rules by opting to "cut right to the bank and pay the fine" (J. Sprohge, unpublished data). Planters show an awareness of the preservationist-developmentalist divide as emerging from, as they contend, "the almighty dollar" (J. Sprohge, unpublished data). Despite this awareness to which many demonstrate a conflicted response, planters' commitment to economic and personal efficiency in their narratives, which I next take up, represents to some degree the restrictions posed by pervasive bifurcated views of nature that separate it from human ways of knowing and dwelling.

\section{Ghost Lines and Dead Walking: Economic Efficiency}

The history of modern economic models of efficiency logics originates in many ways from the work of mechanical engineer Frederick Winslow Taylor during the Progressive Era (1890s-1920s), who laid the groundwork for contemporary ideas about labor efficiency. Taylor is known for developing the human analysis of production, which he termed scientific management, by breaking down individual component machinist tasks into "elementary operations" and timing them with a stopwatch. Taylor broke labor down into quantity (tasks completed) and time, giving rise to the "differential piece rate" system in which workers were paid differentially, earning higher wages for working more efficiently and with higher production and earning less for lower levels of production and taking more time (Haber 1964, 2).

While today's minimum wage standards have virtually eradicated the differential piece rate system, it is important to notions of economic efficiency that planters describe, for a few reasons. The first is simple mimicking of taking a job apart by task "pieces," echoed throughout planters' language as a reference to a cut block of land. The second and more important infusion of Taylorism into planting practices is the elevation of quantified task and time that characterizes planters' relationship to their work, despite their assertions that "no one is going to make you plant." This is captured humorously in Kailen's introductory narrative realization: "I thought: 'oh my god you're supposed to be planting like fifty of these in a minute.' And I started panicking, 'I can't just stand here. Oh god, oh god!'”

Much like Kailen, each planter I interviewed described a typical day of planting in terms of how much, how many, how fast, and how long; planters also showed an awareness of the economy of movement ever 
present in their minds as they worked. Every planter I spoke to described trees numerically: "a box of 18 bundles, bundles of 15 , so there's 270 trees total" (T. Bourlas, unpublished data). And although each planter described themselves as driven by financial gain, many spoke more about speed as their driving factor; as Tamir reiterated, "when you're planting you don't really think about money. You just want to plant more trees and cover your ground and cover ground efficiently." While the time needed to plant one box of trees differed by planter, the notion of efficiency-planting as many trees as possible in the fastest amount of time without sacrificing quality — was an overarching theme that emerged in discussions of the work. To plant efficiently, a planter first has to plant according to density amounts set by the reforestation company:

What they do is they throw plots, have you heard of this? Okay, so checkers have plot cords; planters do too. They're these cords that ... have a loop at one end, so they'll walk out into the land somewhere, plant their shovel, just like stick it in the ground, and put the loop over the shovel, and then they'll walk to the end of the cord and trace a circle around the shovel, and they'll count all of the trees that are inside there. So the first thing that they're checking is how many trees are in the plot, and that's how we determine the spacing of the entire area. So, at the start of the day, we'll be told, oh, we're planting tens today, which means if you are to do a plot, you would find ten trees in that circle, and they say if they find fourteen, that's too many; that means you're spacing too close and they'll tell you that. (D. Cheater, unpublished data)

Planters consistently described this process (i.e., planting sevens or planting eights) as the constraining force on efficiency and what separated "rookie" (first-season planters) from "veteran" planters, articulated well by Ryan, a thirteen-year veteran:

Basically, [you're] doing the exact same thing thousands and thousands of times each day, so you're slowly refining your method; and since you're doing the same thing over and over again, you can shave even a fraction of a second off what you're doing, by the end of the day it really adds up, and you'll have made a lot more money, so working hard is really important, but also just being really efficient in what you do and not wasting any motions at the end of the day you'll be making a lot more money, so a rookie could absolutely kill themselves and work as hard as they possibly could and still make less money than a veteran who just seems to be lazily planting trees, simply for the fact that they've refined their methods so much over many, many seasons and hundreds and thousands of trees. So I would say, yeah, any veteran who's really planting consciously will have given a little thought to what they're doing and will have just refined their method over the years until they're very, very, very efficient and they're not wasting any time doing it. As soon as they put the tree in the ground, 
they know just exactly how much effort they need to do to close the hole acceptably. They're not doing any extra unnecessary work. They've planted enough trees and gotten enough blocks passed that they're not paranoid about their quality. They know what they need to do to have a good tree, so, as I was saying before, riding the line between quality and speed is so important, so they don't spend extra time unnecessarily worrying about quality. They know exactly what they need to do to plant a good tree, and they don't do anything extra, and so as soon as they put the tree in the ground their head is up, and they're scanning for the next good spot in the area. Whereas when I think of rookies, I was actually the foreman for the rookie crew this past year, so I spent a lot of time around them. When I think of rookies the image that comes to my head is standing still and just looking around slowly, trying to get their bearings and figure out where to put the next tree. Whereas veterans are essentially never ever standing still. They're always moving; they, since they've done it so many times, they instantly know where the next tree needs to go and they're constantly in motion. (R. Boldt, unpublished data)

Each planter detailed the importance of not wasting time, giving specific details about how to plan and time an approach to planting a piece as calculating how many trees it would take for planters to get to and from their tree cache, which is where planters "bag up," or pack up boxes of trees they wear on their shoulders (or take water or food breaks, calculated into "bag-up times" [S. Friesen, unpublished data]). The object, planters described, was never to walk any land with an empty bag and to economize every step with planting in mind-each box taking between thirty and forty minutes to plant. As planters explained, the ideal economical, fluid motion of planting one tree-much like motion studies that study worker movement and time-would be a three-step process of opening a hole in the ground with a shovel, bending down and planting a tree, and stomping the hole closed with one stomp, "grabbing trees every two seconds or so" (R. Boldt, unpublished data)the motion of Stephanie Clement's mantra one, two, tree! Any disruption to this process-extra stomps, an empty bag, thinking too long about the next location, difficult soil conditions, a water or food break-cuts into efficiency, so much so that planters developed a vernacular for inefficient planting, referring to "dead walking" and "ghost lines." As James outlined, "You're always planning out how far into the piece these trees are going to get you and how far back it's going to get you from dead walking from the way you planted your first tree to where your last tree is in the bag of the cache" (J. Simpson, unpublished data).

It is perhaps telling about the pervasive logic of efficiency that planters equate inefficiency with death, the end of human productive value. As planters relayed, the most efficient patterning of planting in a cut 
block would be to plant from the uncut tree-line border (or "back") of the block without cutting off any access to the cache planters need to return to periodically throughout the day. Planters thus plant in a grid, flagging seedlings with planting tape to know where they have planted and where they have not, and they never walk over any land without simultaneously planting a tree on it. As Ross put it, "You don't want to make . . . yourself do any dead walking is the term that they use, which is walking when you're not planting. Doing any movement when you're not planting trees as you go is stupid. You want to avoid it if you can” (R. McCannell, unpublished data). Georgia similarly described dead walking in temporal terms: "They call it 'dead walk' over planted trees-that you're kind of wasting time on what you could be planting, so it would be best that you could have a straight square you could always be planting so you're not having to walk over your trees and waste time or forget a little bubble because if you forget a little bubble, then you have to go back and plant it later and then nobody is happy with you because it wastes time" (G. Chappell, unpublished data). Any deviations from planting this "straight square" - that is, back and forth in a grid-are known as "ghost lines," lines that diverge from the standard back and forth of square grid planting and are thus tagged as "incredibly inefficient" (L. Ainsworth, unpublished data).

It is worth spending a moment with the metaphors of ghost lines and dead walking, which appear as vernacular for inefficiency coded within temporal and rhythmic situations of the cut block on the landscape. As I suggest in considering the role of affect in tree planters' descriptions of their work in chapter 3 , the plantation-scape of the cut block is in itself a space of environmental loss, a place of confronting a variety of ghosts that force a different kind of reckoning with the land. This may take various affective shapes: the frustration of inefficiency, bad land, or spatial sense; the bewilderment of needing to gain one's bearings in a wasteland; the rookie moment it takes to grapple with the question where the fuck am I supposed to put the tree. Even these vernaculars that are the most depreciatory of inefficiency show an affectual attunement to the making of plantation spaces.

Yet it's true that tree planters' commitment to efficiency rhetorics was shown in many ways, most notably by readily available descriptions of their work in terms of numerical efficiency measures. Numerical details abound: what price per tree, how many trees per box, how many boxes per bag, how many trees per corded plot density, how many steps to plant a tree, and how much time it takes a planter to plant each box of trees. This, as Clark $(1989,275)$ maintains, is the epitome of the rhetoric: 
"When efficiency takes over, 'goodness' is defined in numerical terms. Whatever is to have value must somehow be converted into a measurable quantity. What cannot be counted is 'of no account'; it is outside the system." While talking to planters, it's true that my interest was piqued far more by what they said that seems, in Clark's terms, to be "of no account"; however, before I attend to those accounts, it is important to look at the way efficiency has become a guiding principle in accounts of tree planting. Here, numerical "goodness" translates to planters' accounts of personal efficiency as not only an economic good but also a social one.

\section{Your "Personal Best": Accounts of Personal Efficiency}

The insidiousness of efficiency is that it has become naturalized as an unquestionable good that has been written into the everyday of modern life, moving from the realm of "technical and managerial" to that of "social and political" (Princen 2005, 84). Today, "efficiency could be a personal attribute as readily as a professional technique" (Princen 2005, 75), writ so indelibly on the psyches of modern citizens as to appear natural and normal despite its ambiguous nature and ability to be manipulated and changed. This is perhaps in no way more apparent than in planters' descriptions of their accounts of financial success from year to year and their adaptation of such success into the rhetoric of personal efficiency - "hard work, thrift, willpower" (Princen 2005, 64) - that characterizes the standard unit by which planting success is measured: the "personal best," or PB.

When efficiency societies and magazines were having their heyday in the 1910s, the principles of efficiency were transformed into a social good, as Hays $(1959,125)$ cites from a 1913 engineering journal: "When humanity shall have learned to apply the common sense and scientific rules of efficiency to the care of body and mind and the labors of body and mind, then indeed we will be nearing the condition of perfect." Personal efficiency, then, was seen as the antithesis to laziness that promised both perfection and plenty through effort and hard work. This principle is described almost verbatim by planters who reflected on planting done during their first, rookie season:

Your first day of planting trees pretty much across the board you make, you know, thirty bucks, forty bucks, for like a ten-hour day; and actually the first day isn't so bad, but the third day is horrible. The first day is kind of fun and exciting because you're learning a new thing and getting out there, but you know on your second or third day you start to realize how little money you are making and how hard you're trying . . . in the 
beginning, you're terrible. And you make no money. You're not even making minimum wage ... But then after a month, you like double the amount of trees that you're planting like every day almost, so you're getting better so, so, so fast and making money all the time, which is nice. But it's just so hard. (G. Chappell, unpublished data)

The first year, it's kind of tougher to make a ton of money because you're learning for half the season, and then the other half of the season you do make some money, but it's not as much as people hear about, so it doesn't really seem all that worth it. (S. Friesen, unpublished data)

The first two weeks of your planting career is [sic] the hardest of all 'cause it's just so frustrating. You're still, you're trying to learn how to do it, and from what I hear, you're steadily, you are pretty steadily improving all the way up to your fourth or fifth year, and then it's just a very, or third or fourth year, sorry, and then you're just a very, like I think you would still improve, getting more efficient at that point but not nearly as much as from your first to second year, second to third year. (L. Rempel, unpublished data)

Well, I can remember about halfway through the year just doing the simple math and figuring out that I had made nothing. If I encounter or took into account my flights out there and the camping equipment I bought and the money I spent just on our days off in terms of food and laundry and new clothes and whatever, then I had made nothing. (T. MacInnis, unpublished data)

My first day I think I made about negative two bucks; they charge you a camp fee of thirty dollars a day for food and transportation and all that stuff. And you obviously, as a competent tree planter, would make that amount back. But as an incompetent tree planter you very well might not. So I think I planted as a box, 270 trees, they were probably twelve cents each, so thirty-five bucks? So I made five dollars, apparently. You know, you know what? I bet I spent six bucks on beer, so negative one [dollar].

(J. Simpson, unpublished data)

Despite the fact that planting is tallied by tree price and infused with the promise of financial gain, it's clear that planters recognize that there is no direct correlation between input and output. Still, planters relay these narratives as evidence of their hard work and perseverance (making little financially but still sticking with the job).

Perhaps because of this inconsistency, planters give a great deal of credence to the idea of the $\mathrm{PB}$, the highest number of trees they had personally ever planted in one day. Although PBs ranged from 2,000 to 5,000 trees planted in one day and are dependent on region, planters described their personal best days as some of the most memorable because it's "the only time you can talk about how many trees you've planted ... that doesn't involve telling how many trees you've planted" 
(G. Chappell, unpublished data). Here efficiency is concerned with numbers without numbers, invested instead on the personal value of hard work as a matter of pride:

Particularly when you're starting to get good, then you become incredibly focused on numbers because that's the measure of your success, that's the measure of how well you're doing compared to other people, and it's a measure of personal achievement. And certainly, if you get a bigger number than you've had in the past, that's a matter of pride. (S. Dyck, unpublished data)

I always looked at it like a game; for me, like I was just trying to be better than myself every day, which obviously you can't do every day, but like when I started it was a thousand trees, and then our camp boss wanted us to be really competitive, she wanted to form a competition just 'cause the more tree[s] you plant in a day, the more efficient the camp runs, so the more money the camp makes and the more money the planter makes, so, I mean, I know that I am benefiting them if I plant more, but I'm also benefiting myself. But I never looked at it like money. I just wanted to plant more trees, and I just took a lot of pride in that. So first I would try to go for 1,000, then I tried to push for two 2,000 and I finally got there, and then I tried to push for 3,000 and I got there. And that was like, that was the mark; once I hit 3,000 I was like, this is where I want to be at. And I hit 4,000 one day in my first year, which I was really happy about, and for days like that, I mean, you get efficient. (N. Friesen Hughes, unpublished data)

One time I planted over nearly 4,000 trees one day, and it was very thrilling to sort of work my ass off and have a personal best for a day . . . Not much there really when you think about it, it's one tree after the next, but it's a very vivid memory and very exciting. I can remember putting my shovel in the ground, putting the tree in the ground, stomping on it, and doing that so quickly and being so efficient with my movement, and then getting back to the cache, emptying the box of trees, filling my bags up, crumpling the box up, putting it away, and nearly running back out to the block, sweat dripping down your face, adrenaline pumping, and then, yeah, at the end of the day being so exhausted, and, you know, I only made like 200 bucks more than I would any other day, but it was, that's very exciting. (T. Bourlas, unpublished data)

As Tamir notes, the financial reward for a PB is not hugely compelling; it is not the difference of thousands of dollars, it doesn't earn a planter a day off or a bonus. Instead, a PB is a way to indicate social status among planters and is couched as a measure of personal pride and individual hard work.

Here efficiency comes full circle, not only as a measure of success in an economic or a managerial realm but also in the realm of the social and the personal, cementing tree planting as a managerial act that constructs efficiency as what Princen $(2005,84)$ terms "a self-evident truth. 
As individuals become ever more efficient, they, and the society they comprise, are better off." The implicit narrative of progress in these descriptions of tree capital, economy of motion, and numericalization of everything from bagging up to grid planting suggests that, indeed, those who plant are bound to think and act in ways that see nature as a market resource and culture as promoting its exploitation (even when they are giving numbers without numbers). We may wonder, then, if there is any room in the lifeworlds of anthropogenic plantation makers to move beyond these dualities. To answer in the affirmative, I draw my hope from Tsing's (2015a) notion of the patchy in the "patchy Anthropocene": that the Anthropocene, as invented through lifeworlds, is inconsistent, uneven, sporadic, irregular, or possibly, as she suggests, inadequate.

\section{DWELLING IN INCONSISTENCIES}

In writing through the omnipresence of the nature-culture split through a delineation of its philosophical roots and transport to contemporary discourses that today overarchingly see nature as a resource, my aim has been to acknowledge the very real cultural and material impact such discourse has on human ways of thinking, knowing, and, in the case of industrial silviculture, working. Tree planters are not outside these pervasive ways of thinking about the world. However, the premises on which this divide rests are unstable, considering how often they are conflated with ideas of the hyper-rational human agent; the de-historicizing of contemporary economics, personal gain, and rampant individualism; the reification of the subject-object split for political or financial advantage; and the unchecked assumption of possibilities for unlimited growth. Erased from this discourse are infinite and real possibilities that have long been dismissed and disparaged by reason and rationality-the vernacular, the material, the parochial and the intensely local, the unreasonable, the perspectival, the sensorial, the illogical or nonsensical, the performative, the ambient.

To move from the discourses of the anthropos that close off possibilities by separating humans from lifeworlds, we must instead allow the limits of these seemingly commonsensical notions of humanism and efficiency to rise to the fore and recognize that dwelling perspectives have "to entail more than a logic" (Rickert 2013, 252) derived from the principle of exteriority. So where might we begin? First, by paying attention to the limits and gaps left to us by privileging humanism and efficiency as the only ways of knowing the world and instead turning deliberately to the particular, the temporal, the qualitative, and 
the heterogeneous; to turn from the ideal of Western individualism as having much explanatory potential and instead toward the living processes of landscapes as generated in movement, in relations, in affects. This work has to a large extent been done for us by those who take a dwelling perspective in their own work, whether by considering the vitality of matter, the posthuman condition, the porosity between interior and exterior, "cross-species interactions or disturbance-based ecologies" (Tsing 2015b, 15), or human-technosphere interaction. ${ }^{21}$ Taken together as applied to the case of tree planting, I call this a new material environmental rhetoric. It means that rather than buy wholeheartedly into the evidence that industrial reforestation workers only see themselves as part of a resource chain anchored in personal profit and secured by promises of unending progress and increased ratios of output to input, our attention is drawn instead to the ways efficiency ratios are "neither self-evident nor is their increase unambiguously 'good"' (Princen 2005, 89). Our attention is drawn instead to the impossibility of the economic man, the nonsensicality of numbers without numbers, the affectual moments of panic and confusion and joy that are bound up in discourses of humanism and efficiency, the persuasive means gathered by nonhuman and inorganic actors. We look, then, to the ambiguous, to the inconsistent, to the planter who speaks in the same breath of efficiency, drain, and performance: "[The pressure to be a good planter is] emotionally draining a little bit because it's like ostensibly the only reason it matters how many trees you plant is because of how much money you make, but that's just not really true. And so, there's this . . kind of like feeling that you really need to perform for this kind of vague reason you can't really put your finger on" (G. Chappell, unpublished data).

In other words, we look to the ambient as the place(s) within which meaning dwells, as the state of being that living in ruin compels, as an "entire way of life materialized in practices and things" (Rickert 2013, 253) that call for our attention when we view tree planting as more than a price per tree in exchange for a stumpage fee: in material human and nonhuman bodies in relation, in feelings and desires and dreams, in soldering lives to machines, all in contribution to inventing the fragmented Anthropocene.

\section{NOTES}

1. "Bräcke" is short for "Bräcke mounds" created by a Bräcke mounder, a large machinic excavator equipped with two spades that mounds dirt into two rows, making land easier to plant. 
2. See, for example, Harvey's (1996) discussion of "The Nature of the Environment" and Cronon's (1995) assertions in Uncommon Ground.

3. See Escobar 2008; Whatmore 2002; Lorimer 2012; Goldman and Schurman 2000; Maffi 2001; Pretty 2007 for representative samples of these arguments as taken up in their respective disciplines.

4. For a fuller discussion of deep ecology and spiritual essentialism, see Braidotti 2013, 86.

5. See also Oelshlaeger 1991.

6. Pilgrim and Pretty 2010, 1; Strathern 1980, 180.

7. For the sake of brevity, I have not included various responses to modernist conceptions of nature in the seventeenth through twentieth centuries; for a fuller discussion, see Oelschlaeger 1991.

8. See also Craig, Yung, and Borrie 2012 for an extensive historical overview of Glacier land claims.

9. For a nuanced discussion of this displacement as it pertains to American national parks, see Keller and Turek 1999.

10. For a discussion of how a "de-humanized nature" historically and contemporarily affects Indigenous landscapes of Amazonia, see Tavares 2016.

11. Tree planters also note this discrepant perspective in consideration of the sonic landscape created by logging roads, as discussed in chapter 4 .

12. See Sandliands 2000, 177-79.

13. Natural Resources Canada 2016.

14. Comparable numbers in the United States are 1.4 percent of the GDP in agriculture, forestry, fishing, and hunting; 1.2 percent in mining; and 1.3 percent in the "utilities" sector (which includes the gas and power industries) (Bureau of Economic Analysis 2016).

15. See also Killingsworth and Palmer's (2012) discussion of Stephen Fox and his historic work on John Muir and the creation of Yosemite National Park.

16. For example, Winthrop 1972.

17. For further discussion of this tension, see Killingsworth and Palmer 2012, 24.

18. See also Descola 2013, xv-xvi.

19. For these discussions, see Gaonkar 1997; Grassi 2001; Althusser 2003; Mailloux 2012.

20. This stems from the "creed" of Robert Ingersoll (2009 [1900], 478), noted humanist and free thinker, who asserted: "Happiness is the only good. The place to be happy is here. The time to be happy is now."

21. See Bennett 2010; Braidotti 2013; Descola 2013; Haff 2013; Iovino and Opperman 2014; Tsing 2015b for detailed discussions of each of these topics. 